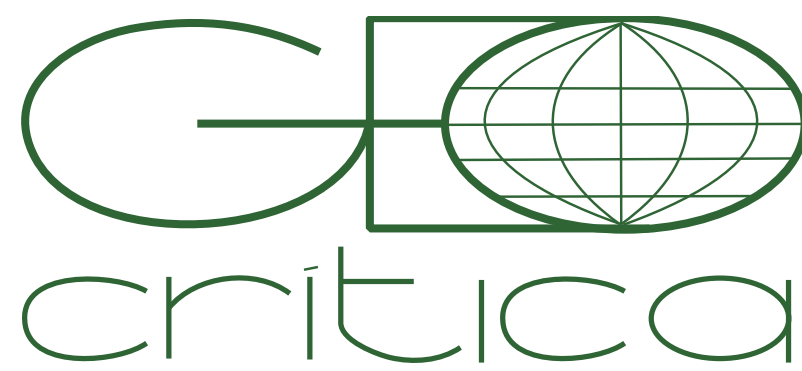

\section{Scripta Nova}

Revista Electrónica de Geografía y Ciencias Sociales Universitat de Barcelona

ISSN: $1138-97$

Vol. 25, Núm. 1 (2021), p. 195-237.

\title{
UNA GEOGRAFÍA REGIONAL DE LOSTIPOS DE HOGARES EN LA EUROPA DE LA SEGUNDA TRANSICIÓN DEMOGRÁFICA
}

\author{
Joaquín Recaño Valverde \\ Departament de Geografia - Centre d'Estudis Demogràfics, Universitat Autònoma de Barcelona \\ joaquin.recano@uab.es
}

Ana Chacón Martínez

Instituto Superior de Enseñanza (ISEN), Universidad de Murcia ana.chacon@um.es

Este artículo se ha desarrollado en el marco del proyecto de investigación "Comportamientos demográficos y estrategias residenciales: apuntes para el desarrollo de nuevas políticas sociales (CSO201679142-R)

\section{Recibido; 12 abril 2018; Devuelto para correcciones: 1 junio 2018; Aceptado: 17 diciembre 2020}

\section{Una geografía regional de los tipos de hogares en la Europa de la Segunda Transición Demográfica (Resumen)}

En este artículo se analiza la distribución geográfica de las estructuras de hogares en Europa, a partir de datos simultáneos y metodológicamente equiparables de 32 países europeos y 1.340 regiones NUTS 3 (Eurostat) correspondientes a la ronda censal de 2010. Con esta información, hemos confeccionado una serie de mapas detallados con la distribución espacial de los tipos de hogares a escala NUTS 3. Para llevar a cabo este trabajo se han empleado técnicas de econometría espacial, análisis de componentes principales y conglomerados. La geografía de los tipos de hogares que emerge tras nuestro análisis constata la existencia de una significativa autocorrelación espacial en todas las formas y estructuras analizadas; es decir, los tipos de hogares no se distribuyen de forma aleatoria en el espacio europeo.

Palabras clave: Estructura de Hogares, Familia, Europa, 2011, NUTS 3.

\section{A regional geography of the household forms in the Europe of the Second Demographic Transition (Abstract)}

This article analyzes the geographical distribution of household structures in Europe, based on simultaneous and methodologically comparable data from 32 European countries and 1,340 NUTS 3 regions (Eurostat) drawn from the 2010 census round. With this information, we build a detailed map of household types to identify those structures which have a higher incidence in the unequal spatial distribution of household forms. To carry out this work, spatial econometric techniques, analysis of principal components, and clusters have been employed. The geography of household types that results from our analysis confirms the existence of a significant spatial autocorrelation for all the household structures analyzed. Thus, the types of households are not distributed randomly in the European territory.

Key w ords: Household Structure, Family, Europe, 2011, NUTS 3. 
Los patrones a través de los cuales las familias y hogares adoptan una determinada estructura y/o forma han experimentado grandes cambios en las sociedades europeas desde la década de los setenta del siglo XX (Buchmann y Kriesi 2011). Los adultos jóvenes se emancipan, se casan y tienen hijos a edades más avanzadas (Gauthier 2007), las probabilidades de no casarse o casarse y no tener hijos han aumentado (Rowland 2007). La cohabitación, el divorcio, los nuevos matrimonios y la monoparentalidad se han vuelto más comunes (Heuveline y Timberlak 2004; Heuveline et al. 2003; Kiernan 1988). Algunos autores hablan de un modelo que ha evolucionado desde una llegada temprana a la adultez de carácter universal , a una emancipación tardía más restringida y múltiple (Billari y Liefbroe 2010). Se crean familias más complejas a través de la maternidad en solitario, la disolución de las uniones, las segundas y terceras uniones con hijos de ambos cónyuges y el incremento dela adopción. Muchos de estos procesos se desarrollan bien entrada la edad adulta y acaban generando múltiples y complejos itinerarios familiares (Thomson 2014; Van Winkle 2018).

Los procesos de transformación de la familia han despertado, desde fechas muy tempranas, el interés de científicos de diferentes disciplinas sociales como la historia, la antropología, la sociología, la ciencia política y, en menor medida, la economía. Todas ellas consideran la familia como una institución social de primer orden.

El estudio histórico de los sistemas familiares permite conocer las normas, valores y prácticas asociadas con la organización de los lazos familiares y de parentesco, fundamentales para la comprensión de las transformaciones sociales. Los sistemas familiares controlan las dinámicas domésticas: ordenan las formas de matrimonio, sucesión, transmisión de la propiedad, los tipos de corresidencia y las reglas de desarrollo de estas prácticas, habitual mente discriminadas por género y edad (Skinner 1997). Este conjunto de reglas sociales se materializa finalmente en una tipología de las estructuras de hogares que serán objeto de indagación en este trabajo. Diferentes autores han adjudicado una significativa diversidad espacial a los sistemas familiares y las tipologías de hogares (Hajnal 1982; Laslett 1983; Todd 1990; Reher 1998). Sorprende, sin embargo, el escaso interés de la geografía por el análisis de la distribución territorial de las tipologías de hogares y familias tanto en España ${ }^{1}$ como en el contexto europeo ${ }^{2}$. Un ámbito de análisis que ha sido reivindicado más bien por historiadores y antropólogos (Laslett 1983; Todd 1990; Reher 1998; Mikelarena 1992).

En este artículo construimos, a partir de información de carácter censal que proporciona el dataware de Eurostat, denominado Censushub, una geografía regional de las estructuras de hogares y de algunas formas familiares en Europa en torno al año 2011. Nos proponemos describir y analizar, con el máximo detalle geográfico posible en la actualidad, la distribución de las diferentes tipologías de hogares a lo largo de Europa y dibujar un mapa de las viejas y nuevas estructuras de hogares que emergen y se consolidan durante la denominada Segunda Transición Demográfica (STD) (Van

1 Con la excepción de trabajos como los de Solsona y Treviño 1990.

2 Podemos ver análisis geográficos de la distribución territorial de las formas familiares por parte de geógrafos en Duranton et al. 2009 y Pfirsch 2011. 
de Kaa 1987; Lesthaeghe 2010), destacando las continuidades y rupturas en el espacio europeo que, por vez primera, es descrito con información homogeneizada de 32 países y 1.340 unidades regionales NUTS 3.

El artículo se estructura en siete secciones. Tras la introducción, se presenta un estado de la cuestión, seguido de un apartado en el que se describen las fuentes y metodología estadística empleada. A continuación, se inicia el análisis de los resultados, estructurados en cinco bloques: un primer bloque que contempla una aproximación a la distribución territorial de las tipologías de hogares en Europa desde la perspectiva nacional; un segundo bloque que ofrece una geografía descriptiva de la distribución espacial de las estructuras de hogares a escala NUTS 3; un tercer bloque que aplica técnicas de econometría espacial para la localización de clústeres espaciales de las diferentes estructuras de hogares; ; un cuarto bloque donde procedemos a la identificación de los factores que explican la desigual composición geográfica de los hogares mediante la aplicación de un análisis de componentes principales. A continuación, introducimos un análisis de conglomerados que tiene como objetivo la construcción de una agrupación de áreas geográficas NUTS 3 con una composición similar en la estructura de hogares. El artículo concluye con un apartado que recoge las principales conclusiones del trabajo y una bibliografía con las referencias empleadas.

La articulación del texto se regirá por el siguiente esquema analítico. En primer lugar, vamos a construir diferentes mapas de las tipologías de hogares a escala regional NUTS 3 referidas al año 2011; cartografía que supone una novedosa aportación a la geografía de los hogares de Europa. Por primera vez, va a ser posible comparar de forma simultánea las estructuras de hogares de 32 países y 1.340 áreas regionales. En segundo lugar, los indicadores estadísticos que cal culamos sobre la distribución de las tipologías de hogares en las regiones NUTS 3 nos van a permitir establecer el grado de heterogeneidad de las estructuras de hogares a escala nacional y europea. En ese sentido, podremos establecer si la óptica nacional de análisis oculta una mayor variabilidad subnacional de esas estructuras que la que se desprende de la comparación entre países. En tercer lugar, intentaremos confirmar si las estructuras de hogares tradicionales y emergentes ocupan los espacios geográficos que sugiere la literatura científica más reciente. En cuarto lugar, la estadística espacial nos permitirá confirmar la existencia de autocorrelación espacial en esas estructuras y si existen fronteras geográficas nacionales entre los distintos tipos de estructuras de hogares o, por el contrario, algunas pautas de las estructuras consideradas muestran continuidades transnacionales y dónde se localizan. En todo caso, este tipo de metodología nos permitirá dibujar los principales clústeres geográficos de las estructuras de hogares en Europa. Posteriormente, identificaremos mediante el análisis factorial, qué tipologías de hogares explican las diferencias de estructuras de hogares entre las regiones europeas. Por último, elaboraremos a partir del análisis de

3 De forma similar a los trabajos desarrollados por López-Gay et al . 2015. 
conglomerados una tipología espacial de las estructuras de hogares dominantes en Europa a escala NUTS 3.

En este artículo se intentará corroborar, matizar o refutar desde una perspectiva geográfica y una escala territorial más apropiada, correspondiente a la división en regiones NUTS 3, el retrato que ha dibujado la literatura científica sobre la distribución espacial de los tipos de hogares en Europa.

\section{Notas sobre la geografía de la familia en Europa}

La tradición dominante en los estudios sobre las tipologías de estructuras familiares se ha centrado básicamente en el análisis de las tipologías familiares. Es por ello que centramos nuestra primera aproximación teórica a las contribuciones realizadas en el ámbito de los estudios sobre la familia. Estos resultados son bastante orientativos del devenir en la evolución de las tipologías de hogares.

Los sistemas familiares son conjuntos de normas, valores y prácticas que regulan la organización de los vínculos familiares. La variación espacial de los sistemas familiares está ligada a la evolución de los contextos históricos, sociales e institucionales en los que se constituyen los hogares, tanto familiares como no familiares (Hollinger y Haller 1990; Skinner 1997; Reher 1998; Das Gupta 1999; Mason y Oppenheim 2001; Therborn 2004). A pesar de que la familia ha tenido siempre una relación cercana con el espacio, los geógrafos han tenido poco interés en su estudio (Pfirsch 2011). Las consideraciones teóricas esbozadas por la sociología de la familia han obstaculizado durante mucho tiempo la incorporación del espacio a los análisis sobre la familia contemporánea. Por ejemplo, la propuesta teórica de Durkheim estimaba una progresiva desvinculación de la institución familiar y el territorio bajo el efecto de la urbanización y la industrialización. La familia contemporánea, centrada en las relaciones personales entre individuos independientes económicamente, rompería el enraizamiento espacial y comunitario que relacionaba históricamente el patrimonio y la familia en las sociedades rurales (Durkheim 1921; Parsons 1943). Posteriormente, otros teóricos de la misma disciplina consideraron que la reducción delas disparidades espaciales de las estructuras familiares sería producto tanto de la convergencia de las pautas demográficas entre países (disminución del matrimonio, aumento de la inestabilidad conyugal, desarrollo de familias monoparentales y reconstituidas, reducción de la fecundidad y el tamaño de los hogares, etc.) como del auge del individualismo (Roussel 1992). Sin embargo, una serie de estudios realizados durante las últimas décadas han desafiado en gran medida estas dos ideas (Van Winkle 2018). La urbanización, la industrialización y el individualismo no han debilitado el parentesco, que mantiene su protagonismo como fuente de cohesión social y espacial, pero lo han hecho más complejo porque las relaciones entre un individuo y sus parientes son objeto ahora de negociación constante; las relaciones familiares se reorganizan y se reinterpretan según las aspiraciones individuales. Por otra parte, el parentesco se ha desligado de los principios, obligaciones y prohibiciones religiosas en el matrimonio. Además de este redescubrimiento del parentesco, también ha nacido 
un creciente interés por la geografía de la familia y de las estructuras de los hogares desde el ámbito de la demografía, que se ocupa ahora de estudiar la evolución de los vínculos familiares en el tiempo y el espacio desde la perspectiva singular del ciclo de vida y su manifestación en la edad (Bonvalet y Gotman 1999; Mulder y Cooke 2009; Hank 2007).

Dos tipos de contribuciones van a ser consideradas en este estado dela cuestión 4 . En primer lugar, las que han establecido divisiones generales y particulares sobre la distribución espacial de las formas familiares y las estructuras de hogares en Europa. En segundo lugar, las que han tenido en cuenta los mecanismos sociodemográficos e institucionales que han influido en los cambios más recientes en la constitución y transformación de los modelos familiares y de hogares, especialmente a través de la Transición Demográfica (TD) y la denominada posteriormente Segunda Transición Demográfica (STD).

Las contribuciones al estudio de la evolución de la familia en Europa son numerosas en la escala nacional (Roussel 1986 y 1992; Gullestad y Segalen 1995; Keilman 1988; Reher 1996; Ruggles 2009), pero mucho menos abundantes cuando descendemos a escalas territoriales menores, especialmente aquellas que consideran simultáneamente el conjunto del espacio europeo. En las próximas páginas, veremos algunas de las principales contribuciones al estudio de la distribución espacial de las formas familiares en Europa. Esta última, ha sido la óptica dominante por encima de los estudios sobre las estructuras de hogares. Sobre la diferenciación entre hogar y familiar volveremos más adelante en el apartado de fuentes y metodología.

El trabajo seminal deJ ohn Hajnal (Hajnal 1965) estableció por vez primera una división geopolítica de la nupcialidad con importantes implicaciones en la geografía de la familia. Las marcas distintivas del patrón de matrimonio europeo establecidas por Hajnal fueron una alta edad al contraer matrimonio y una elevada proporción de personas que nunca se casaban. El "patrón europeo" dominaba la mayor parte de Europa, excepto en la zona oriental y el sudeste del continente. En 1900, este patrón se extendía al oeste de una línea imaginaria que iba aproximadamente de San Petersburgo a Trieste, extensa zona en la cual el matrimonio era tardío y menos frecuente. Por el contrario, al este de esa línea el matrimonio era casi universal y temprano. Algunas investigaciones posteriores han reclamado la existencia de un patrón particular en la Península I bérica (Chacó 1991) y el sur de Italia (Viazzo 2003) con características intermedias entre el "patrón europeo" y el de los países del Este.

Otros autores establecieron posteriormente divisiones geográficas más complejas en las que las diferencias entre los sistemas familiares en Europa se establecían de acuerdo con cuatro grandes regiones: el norte y noroeste, las regiones centrales, las zonas meridionales y, finalmente, los espacios orientales (Laslett 1983; Heady et al. 2010.). La primera de estas zonas, la región norte-noroeste, integrada por los Países Bajos, Suecia y Dinamarca, se caracterizaba por vínculos familiares débiles,

4 Vamos a obviar, por tanto, los numerosos estudios local es y regional es que no dan cuenta de una visión general de la distribución de las formas familiares en Europa. 
altos porcentajes de cohabitación y un tamaño del hogar relativamente pequeño. Por el contrario, los sistemas familiares en el sur de Europa, como España, Italia y Grecia, estaban marcados por fuertes lazos de parentesco, bajo niveles de cohabitación y, en promedio, estructuras domésticas más complejas (Reher 1998; Heuveliney Timberlake 2004; Kalmijn 2007; Micheli 2012). Los países europeos de la región central como Alemania y Francia oscilaban a menudo entre ambos registros (Reher 1998; Heady et al. 2010; Monkediek y Bras 2014); mientras que en la Europa del Este se parecía a los sistemas familiares del sur de Europa con la excepción de que el matrimonio se producía a edades más tempranas y las tasas de divorcio eran mucho más altas (Kalmijn 2007).

En su influyente artículo, David Reher (Reher 1998) identificó dos sistemas familiares extremos en Europa: unas regiones con lazos familiares fuertes situadas en la Europa mediterránea, donde las relaciones entre parientes eran cercanas y el grupo familiar había tenido tradicional mente una prioridad sobre el individuo, y las regiones con lazos familiares débiles, localizadas en el norte y centro de Europa, en las que las relaciones entre los parientes tenían menor entidad y los valores individuales habían sido dominantes (Inglehart 2008).

Las investigaciones del historiador E. Todd (Todd 1990 y 1999), merecen mención especial por la inmensa y provocativa obra generada en torno a la clasificación de los sistemas familiares en el mundo y, en especial, en Europa. En sus trabajos aborda el estudio de las estructuras de los hogares desde una perspectiva antropológica e histórica, ofreciendo un especial protagonismo a la dimensión geográfica de las estructuras familiares. Todd ha clasificado los tipos de familia a partir de dos principios de organización. Primero, las familias difieren en cómo interactúan padres e hijos. En un extremo, los hijos abandonan el hogar a una edad adulta temprana y se independizan de la autoridad paterna. En el otro extremo, los hijos permanecen bajo la autoridad de sus padres hasta edades avanzadas, incluso después de casarse. La primera relación entre padres e hijos puede considerarse como "liberal" mientras la segunda se definiría como "autoritaria". El segundo principio de organización se refiere a la naturaleza de la relación entre los hermanos. En un extremo, los hermanos pueden ser tratados como iguales, mientras en la otra opción, los padres pueden favorecer a un hijo en particular (frecuentemente el varón primogénito) a expensas de los demás. A partir de estas premisas, las familias pueden caracterizarse como "igualitarias" o "desiguales". Donde la autoridad familiar era fuerte, el tipo de familia se denominaba familia extensa, en contraste con la familia "nuclear", en la que la autoridad familiar era débil.

Todd localizó con datos censales de los años 1950 y 1960 una serie de áreas geográficas de carácter rural, en las que la base económica era la agricultura y una elevada proporción de hijos adultos vivían con sus padres. En estas regiones, la forma dominante de las estructuras de hogares correspondía a las familias extensas. La preval encia de este tipo de familias se extendía por la Bretaña francesa, el noroeste de España, Gales y Escocia, coincidiendo con áreas donde las poblaciones celtas se habían 
refugiado hacía dos milenios. El área de familias igualitarias se localizaba en el centro de Italia y se relacionaba con el área de la civilización etrusca en la época prerromana.

Para medir las familias igualitarias, el indicador clave de la igualdad y la desigualdad se basó en lo que sucede con la herencia de la propiedad familiar: la igualdad era más fuerte cuando la propiedad familiar se dividía equitativamente entre los hermanos. Todd desarrolló otros tipos familiares hasta un número de cinco. No obstante, el interés de sus trabajos reside en su intento de caracterización geográfica de los sistemas familiares a partir de un esquema conceptual previo, que tenía poco que ver con las formas familiares más modernas que anal izamos en este trabajo.

En los últimos años, destacan dos trabajos desarrollados por geógrafos que hemos recogido como referencias de la literatura científica en el ámbito de la geografía de la familia europea. El primero de ellos (Duranton et al. 2009), examina la asociación entre las formas familiares y una serie de indicadores demográficos, educativos, sociales y económicos en todas las regiones de Europa a escala NUTS 2, una escala regional próxima a la de las comunidades autónomas españolas. Los autores utilizan la clasificación de los sistemas familiares de Emmanuel Todd e identifican los posibles vínculos entre los tipos de familia y las disparidades regionales en el tamaño del hogar, el nivel educativo, el capital social, la participación laboral femenina, la estructura de los sectores económicos, la riqueza y la desigualdad. En este caso, la tipología de la estructura familiar dominante en un espacio geográfico concreto se convierte en una variable explicativa de las disparidades sociales y económicas de las regiones europeas, en la línea de las tesis planteadas por los trabajos de Todd (Todd 1990 y 1999). Los investigadores han asumido tradicionalmente que el impacto de las estructuras familiares tiende a ser menor que el de otras instituciones sociales y económicas. Sin embargo, estos autores defienden que la distribución geográfica de las estructuras familiares, algunas de las cuales se remontan al período medieval, han influido de forma inequívoca en el origen y desarrollo de las disparidades regionales europeas contemporáneas en materia de indicadores sociodemográficos y económicos. Que esos vínculos permanezcan, a pesar de la influencia del Estado moderno y del impacto de las migraciones, sugiere que tales estructuras familiares son extremadamente resistentes a los cambios temporales y han acabado arraigando dentro de las instituciones sociales y económicas de ciertas regiones europeas. Estaríamos, por tanto, ante una prueba tanto dela resistencia y continuidad temporal de las estructuras como de la especificidad territorial de algunas formas familiares en diferentes regiones europeas.

El trabajo de Pfirsch (Pfirsch 2011), centrado en la geografía de la familia en el sur de Europa, argumenta que los países mediterráneos conservan unas estructuras de grupos familiares muy particulares en el continente, que destacan tanto desde el punto de vista de la composición de los hogares como de los patrones de formación familiar (peso del matrimonio, retraso en la salida de los adultos jóvenes, baja fecundidad estructural). La familia también se presta, según el autor, a una segunda lectura geográfica, centrada en las relaciones de parentesco y su territorialización a escala local. Aquí nuevamente, los países del sur de Europa constituyen un espacio donde 
sobresalen los "vínculos familiares fuertes", especialmente en España e Italia, caracterizados por la proximidad residencial entre los miembros de una misma familia, en el sentido de las tesis expuestas por Reher (Reher 1998). La permanencia del modelo familiar del sur de Europa, resultaría, sobre todo, de un consenso social sobre la distribución de papeles particulares entre el Estado, el mercado y la familia, establecidos en el período de la posguerra para hacer frente a una urbanización rápida e intensa.

Como hemos descrito, la literatura científica ha dibujado a grandes trazos la distribución geográfica de las formas familiares más tradicionales. En las próximas páginas, vamos a identificar las contribuciones científicas que han indagado sobre los factores demográficos e institucionales que explican la aparición y consolidación delas nuevas formas familiares y estructura de hogares y su particular distribución territorial en Europa. Para ello vamos a emplear como hilo argumental tanto la teoría de la Segunda Transición Demográfica (STD) como la distribución geográfica de los regímenes de bienestar en el conjunto de Europa.

\section{La Segunda Transición Demográfica (STD) y los regímenes de bienestar como factores de los cambios recientes en las estructuras familiares y de hogares europeas}

La construcción de las estructuras de hogares y familias depende de la interacción de diferentes mecanismos demográficos, sistemas legales, pautas culturales, antropológicas y contextos religiosos (Van de Kaa 1987; Lesthaeghe 2010).

La Transición Demográfica en su vertiente más clásica (TD) (Livi Bacci 1990) trajo consigo una disminución de la fecundidad (número de hijos) y un alargamiento de la esperanza de vida, esta última con importantes efectos sobre el ciclo de vida de personas y familias: un mayor nivel de supervivencia de las personas y por extensión de los matrimonios, disminuyó el número de viudas jóvenes con hijos y decrecieron significativamente los parientes colaterales, al reducirse el número de hermanos y primos. La disminución conjunta de la fecundidad y la mortalidad provocó el paso de una estructura del parentesco dominada por las relaciones horizontales, a familias caracterizadas por relaciones de parentesco basadas en la verticalidad (Keilma 2003). Estos cambios favorecieron a largo plazo la hegemonía de las formas familiares de estructura nuclear. La desigual cronología regional en el desarrollo de la Transición Demográfica estableció las primeras desigualdades en el panorama geográfico de las estructuras familiares. A grandes rasgos, la convergencia territorial de estas primeras transformaciones demográficas en Europa finalizaría en los años cincuenta del siglo XX (Chesnais 1986).

Completada esta primera fase, la denominada "Segunda Transición Demográfica" (STD) (Lesthaeghe y Van de Kaa 1986; Van de Kaa 1987), se caracteriza por cambios de carácter más cualitativo. El primero es la extensión de nuevos comportamientos que eran poco frecuentes en los años 70 del siglo XX, como el divorcio, la convivencia en parejas no casadas y el nacimiento de los hijos entre 
cohabitantes. El segundo componente de la STD es el retraso en la formación de la unión y la maternidad como características más peculiares. El demógrafo holandés Van de Kaa (Van de Kaa 1987) postuló el establecimiento del nuevo régimen demográfico a través de cuatro fases o transiciones: del matrimonio a la cohabitación, de las relaciones centradas en los niños a las relaciones centradas en las parejas, de la anticoncepción a la concepción para la autorrealización y de un paisaje familiar uniforme a un mosaico de familias plurales. Para los defensores de la STD, la explicación de las diferencias geográficas contemporáneas de las estructuras familiares en Europa estaría relacionada, fundamentalmente, con la existencia de ritmos desiguales en la evolución regional de la Segunda Transición Demográfica.

Los defensores de la STD han utilizado también argumentos institucionales para dar cuenta de la variación espacial en la evolución del comportamiento demográfico de la familia. Lesthaeghe (Lesthaeghe 2010) arguyó que los fundamentos de los patrones tradicionales de formación familiar se debilitarían primero en democracias del mercado liberal igualitario que respetan la elección individual. En el centro de este razonamiento se encuentra la proposición de que los regímenes de bienestar, el mercado laboral, las instituciones del mercado y los sistemas educativos, todos ellos interconectados, tienen una gran influencia en la configuración de los itinerarios familiares y la constitución de los hogares.

La tipología sobre "los tres estados del capitalismo de bienestar" de EspingAndersen (Esping-Andersen 1990) ha sido también ampliamente utilizada como heurística para clasificar y comparar las evoluciones familiares de los países europeos.

Los estados de bienestar socialdemócratas de los países escandinavos fueron precursores en la implementación de las políticas familiares, lo que redujo las diferencias de género y las dependencias intergeneracionales, permitiendo una mayor libertad en la formación y diversidad de las formas familiares (Lohmann y Zagel 2016).

Contrariamente, los sistemas de protección social y las políticas familiares en los países "conservadores" de la Europa continental incentivaron el esquema parsoniano de división del trabajo entre el hombre proveedor y el ama de casa. Muchos países de la Europa occidental y central implementaron subsidios familiares por hijos y las licencias de maternidad (Gauthier 2007). La concentración de la política familiar en los subsidios familiares y la licencia de maternidad, en lugar del cuidado de los niños y la licencia paterna, incentivaba la formación familiar tradicional, limitando la participación femenina en el mercado laboral (Gottschall y Bird 2003). En estos contextos, el divorcio y la monoparentalidad eran interpretados como factores de riesgo para las mujeres.

En el sur de Europa (Ferrera 1996), la influencia de las iglesias católica y ortodoxa contribuyó a la producción de un modelo de bienestar con la familia como eje central (Flaquer 2000). Estos estados de bienestar familiares también se caracterizan por una segmentación del mercado de trabajo y tasas de actividad femeninas muy bajas. Por consiguiente, los procesos que generaban complejidad familiar eran menos probables en el contexto mediterráneo. La dependencia de las familias para asegurar el bienestar individual en las regiones mediterráneas ha 
conducido, a menudo, a una drástica demora en la edad de emancipación del hogar paterno.

En los países del Este de Europa, las ayudas eran comparables con las de los países socialdemócratas durante la etapa del Socialismo de Estado. Sin embargo, muchos de los países de la antigua órbita soviética alentaron el matrimonio precoz e implementaron políticas pronatalistas (Fodor et al. 1997; Kreyenfeld 2004), incentivando así a la familia tradicional.

En resumen, las instituciones características de la socialdemocracia en los estados de bienestar redujeron los riesgos de exclusión social vinculados a patrones complejos deformación familiar: uniones consensuales, monoparentalidad y divorcio; fomentando nuevas formas familiares. El familiarismo en el sur de Europa y el natal ismo duranteel Socialismo de Estado en la Europa oriental promovieron patrones familiares menos complejos, animando el matrimonio precoz y la maternidad. Por lo tanto, era esperable que las trayectorias familiares fueran más complejas y diferenciadas en lo social en países gobernados por la socialdemocracia (Suecia y Dinamarca), seguidas por los países conservadores (Austria, Alemania Occidental, los Países Bajos, Francia, Suiza y Bélgica), y menos diferenciada en los países del sur de Europa (España, Italia y Grecia), así como en los países del Este (República Checa, Polonia y este de Alemania), aunque en estos últimos lugares la incidencia del divorcio fuera un factor importante a tener en cuenta que provocó la aparición de familias monoparentales.

\section{Fuentes y metodología}

El censo constituye la fuente por excelencia que han empleado las distintas disciplinas sociales para el estudio de la evolución temporal de las estructuras de hogares y las formas familiares. Su principal ventaja frente a las encuestas es la exhaustividad territorial que permite la confección de tipologías de hogares en diferentes escalas geográficas hasta el nivel de sección censal. El censo también proporciona la posibilidad de vincular información educativa, económica y migratoria de los individuos con la de otros integrantes del hogar, pertenezcan o no al núcleo familiar. Entre los inconvenientes de esta fuente, se encuentra que el censo es una fotografía de la estructura de hogares, es decir, una observación transversal y por tanto estática que no identifica los fenómenos dinámicos que intervienen en su transformación. No obstante, los anal istas sociales realizan observaciones de la evolución de los hogares a partir de las "fotografías" sucesivas que proporcionan diferentes censos.

En las últimas décadas, la estadística ha tendido a identificar hogar con vivienda o residencia principal. El hogar se define, en esta línea, como el conjunto de personas que resi den en la misma vivienda, comparten gastos comunes por el uso de la vivienda y/o gastos de alimentación. La familia, en cambio, es el grupo de personas que residen en la misma vivienda, comparten algunos gastos en común y están vinculadas por lazos de parentesco sean de sangre o políticos. Un hogar comprende a todos los ocupantes de una residencia principal, independientemente de los lazos familiares. Un 
hogar puede constar de ninguna familia, una familia o varias familias. Es importante señalar que los datos que suministra Eurostat y que hemos empleado en este trabajo permiten identificar los tipos de hogares familiares y no familiares. Entre los primeros, es posible determinar claramente las parejas $\mathrm{y}$, por tanto, las familias nucleares (ver tabla 2); sin embargo, es imposible con las tabulaciones ofrecidas detectar las denominadas familias extensas o complejas puesto que no se establece la naturaleza de la relación entre los distintos núcleos familiares que la componen. Esta es una limitación que no permite aplicar metodologías de clasificación como las de Laslett (Laslett y Wall 1972) y que nos obligan a primar en el artículo la óptica del hogar y no la de familia 5 .

Los datos empleados en este trabajo proceden de una explotación de la base de datos Censushub de Eurostat sobre el Censo de 20116. Estos datos permiten por vez primera realizar una comparación simultánea ${ }^{7}$ de las estructuras de hogares de 32 países europeos en fechas muy recientes y construir un retrato geográfico detallado de la familia europea contemporánea (tabla 1). Como subrayaba R. Wall, la posi bilidad de comparar la situación demográfica de varios países a partir de datos censales se topaba rápidamente con el tema de las nomenclaturas complejas aplicadas en cada censo (Wall, 1992). En el caso que nos ocupa, las tabulaciones europeas del censo de 2011 responden a una metodología común elaborada conjuntamente por Eurostat y los institutos nacionales de estadística con el objetivo de armonizar las estadísticas censales comunitarias y son, por lo tanto, datos plenamente comparables.

La población objeto de estudio son los hogares privados definidos como unidades domésticas de consumo a través de la vivienda de residencia. La óptica de análisis de este trabajo se refiere, fundamentalmente, a la tipología de hogares, más concretamente a las proporciones que representan las distintas estructuras de hogares en cada unidad geográfica considerada (NUTS 3). No se tiene en cuenta, por lo tanto, la ponderación de la población. De esta manera, un hogar unipersonal tiene la misma consideración estadística que una pareja con hijos, porque nuestro interés se centra en la taxonomía de los tipos de hogares y su manifestación en el territorio.

\footnotetext{
5 Una definición más detal lada de los conceptos de hogar, familia y vivienda aplicados por Eurostat en la ronda censal de 2010 puede verse en:

https://ec.europa.eu/eurostat/cache/metadata/en/cens_11r_esmscs.htm

6 Cabe señalar que los datos del censo difundidos no son microdatos, son datos agregados estructurados de acuerdo con un sistema de tabulaciones acordadas previamente a la realización del censo de 2011 por los diferentes institutos de estadística. Las características de este dataware (almacén de datos) pueden verse en: https://ec.europa.eu/CensusHub2/query.do?step=selectHyperCube\&qhc=false..
}

7 En el enlace siguiente se puede consultar los detalles correspondientes a las definiciones empleadas en los censos de cada país para hogares y familias https://ec.europa.eu/CensusHub2/metadata.do es. 
Tabla 1. Glosario de siglas y número de unidades NUTS3 que integran cada país, Europa circa 2011

\begin{tabular}{|l|l|l|l|l|l|l|l|l|}
\hline SIGLAS & PAÍSES & NUTS3 & SIGLAS & PAíSES & NUTS3 & SIGLAS & PAísES & NUTS3 \\
\hline AT & Austria & 35 & FI & Finlandia & 19 & MT & Malta & 2 \\
\hline BE & Bélgica & 44 & FR & Francia & 96 & NL & Países Bajos & 40 \\
\hline BG & Bulgaria & 28 & HR & Croacia & 21 & NO & Noruega & 19 \\
\hline CH & Suiza & 26 & HU & Hungría & 20 & PL & Polonia & 66 \\
\hline CY & Chipre & 1 & IE & Irlanda & 8 & PT & Portugal & 30 \\
\hline CZ & República Checa & 14 & IS & Islandia & 2 & RO & Rumanía & 42 \\
\hline DE & Alemania & 412 & IT & Italia & 110 & SE & Suecia & 21 \\
\hline DK & Dinamarca & 11 & LI & Litchestein & 1 & SI & Eslovenia & 12 \\
\hline EE & Estonia & 5 & LT & Lituania & 10 & SK & Eslovaquia & 8 \\
\hline EL & Grecia & 51 & LU & Luxemburgo & 1 & UK & Reino Unido & 139 \\
\hline ES & España & 59 & LV & Letonia & 6 & Total & Europa & 1359 \\
\hline
\end{tabular}

Fuente: Elaboración propia a partir de los datos obtenidos en Censushub2:

https://ec.europa.eu/CensusHub2/query.do? step=selectHyperCube\&qhc=false

La selección de las unidades territoriales de análisis no resulta un tema sencillo, depende, esencialmente, de la disponibilidad de información y de la dimensión demográfica de las unidades consideradas. La agregación de datos correspondiente a los países que componen este estudio (32) ${ }^{8}$ y otras escal as regionales consideradas por Eurostat, NUTS 1 (92) y NUTS 2 (284), no aseguran una suficiente variación espacial intra-nacional en 2011, por ello hemos seleccionado la escala regional NUTS 3, un tipo de unidad que garantiza a la vez la variabilidad territorial y la significación estadística de los indicadores. Final mente, hemos recabado información acerca de 1.359 unidades territorial es NUTS 3 pertenecientes a los 32 países que aparecen descritos en la tabla 19 . En cuanto a la dimensión temporal, las fechas censales varían entre el 1 de enero de 2011 y el 1 de enero de 2012, lo que supone en la práctica la simultaneidad temporal de la observación. La clasificación de hogares empleada en este trabajo corresponde a la estándar que emplean los institutos de estadísticas europeos. En el artículo se ha distinguido entre los hogares familiares (con la existencia al menos de un núcleo familiar) y los hogares no familiares, que agrupan a los hogares unipersonales, con distinción dela edad, y los hogares multipersonales, aquellos donde conviven personas sin que exista ningún núcleo familiar. Como formas familiares se han identificado las parejas casadas, las uniones consensuales y las familias monoparentales, distinguiendo en todas ellas si tienen hijos o no y si estos son menores o mayores de 25 años y, finalmente, los hogares formados por 2 o más familias. En el caso de los hogares monoparentales se ha tenido en cuenta si la persona que encabeza este tipo de hogar es una mujer o un hombre. Una relación completa de los tipos de hogares empleados

8 En la tabla 1 se muestran las siglas oficiales que emplea Eurostat para identificar los 32 países.

9 No se han tenido en cuenta los territorios de ultramar de Francia y al gunas otras regiones NUTS 3 que no han proporcionado la información demandada, lo que reduce a 1340 las unidades anal izadas. 
se muestra a continuación en la tabla 2. Por otra parte, en este texto, de acuerdo con la teoría de la Segunda Transición Demográfica se consideran formas familiares modernas, los hogares unipersonales de jóvenes, las familias monoparentales y las uniones consensuales. En el otro extremo, las formas tradicionales estarían más ligadas a las parejas casadas con hijos (Van de Kaa 1987).

Tabla 2. Tipología de hogares empleada en el estudio

\begin{tabular}{|c|c|}
\hline Siglas & Tipos de hogares \\
\hline $\mathrm{C} 1$ & Hogares no familiares \\
\hline $\mathrm{C2}$ & Hogares unipersonales \\
\hline $\mathrm{C} 22$ & Hogares unipersonales masculinos de 15 a 49 años \\
\hline $\mathrm{C} 23$ & Hogares unipersonales masculinos de 50 a 64 años \\
\hline $\mathrm{C} 24$ & Hogares unipersonales masculinos de más de 65 años \\
\hline $\mathrm{C} 25$ & Hogares unipersonales femeninos de 15 a 49 años \\
\hline C26 & Hogares unipersonales femeninos de 50 a 64 años \\
\hline $\mathrm{C} 27$ & Hogares unipersonales femeninos de más de 65 años \\
\hline $\mathrm{C} 28$ & Hogares unipersonales ambos sexos de 15 a 49 años \\
\hline $\mathrm{C} 29$ & Hogares unipersonales de ambos sexos de más de 65 años \\
\hline C3 & Hogares multipersonales \\
\hline $\mathrm{C} 4$ & Hogares familiares \\
\hline $\mathrm{C} 5$ & Hogares unifamiliares \\
\hline C6 & Parejas casadas \\
\hline $\mathrm{C7}$ & Parejas casadas sin hijos \\
\hline C8 & Parejas casadas con hijos menores de 25 años \\
\hline C9 & Parejas casadas con hijos mayores de 25 años \\
\hline $\mathrm{C} 10$ & Uniones consensuales \\
\hline $\mathrm{C} 11$ & Uniones consensuales sin hijos residentes \\
\hline $\mathrm{C} 12$ & Uniones consensuales con hijos menores de 25 años \\
\hline $\mathrm{C} 13$ & Uniones consensuales con hijos mayores de 25 años \\
\hline $\mathrm{C} 20$ & Hogares Monoparentales \\
\hline $\mathrm{C} 14$ & Hogares monoparentales masculinos. \\
\hline $\mathrm{C} 15$ & Hogares monoparentales masculinos con hijos menores de 25 años \\
\hline $\mathrm{C} 16$ & Hogares monoparentales masculinos con hijos mayores de 25 años \\
\hline $\mathrm{C} 17$ & Hogares monoparentales femeninos. \\
\hline $\mathrm{C} 18$ & Hogares monoparentales femeninos con hijos menores de 25 años \\
\hline $\mathrm{C} 19$ & Hogares monoparentales femeninos con hijos mayores de 25 años \\
\hline C30 & Hogares monoparentales ambos sexos con hijos mayores de 25 años \\
\hline $\mathrm{C} 21$ & Hogares con 2 o más familias \\
\hline
\end{tabular}

Fuente: Elaboración propia a partir de los datos obtenidos en Censushub2:

https://ec.europa.eu/CensusHub2/query.do? step=selectHyperCube $\&$ qhc=false 
En los próximos párrafos se describen por orden de aplicación las diferentes técnicas de análisis estadístico y espacial aplicadas en el artículo ${ }^{10}$.

La primera de las técnicas empleadas es el análisis exploratorio de datos espaciales (AEDE) (Anselin 1995), una técnica estadística que permite tratar, en nuestro caso, los datos de las regiones NUTS 3, como partes de una estructura territorial donde se establecen relaciones de vecindad, a partir de las cuales es posible determinar la existencia o no de asociación espacial entre áreas. Las relaciones de vecindad se establecen a partir de un criterio especificado por el investigador en función de la distancia o la contigüidad. Los indicadores de asociación espacial miden el grado de similitud de una unidad respecto a sus unidades vecinas a través de una matriz de pesos que determina qué áreas son contiguas de otras. En este estudio hemos optado por un criterio de contigüidad denominado rook de primer orden, el cual considera que toda NUTS 3 tiene como vecinos a regiones NUTS 3 que comparten con ella un límite extenso ${ }^{11}$. Se trata, en este caso, del criterio que mejor ajusta los resultados de manera más parsimoniosa.

Hemos estimado el grado de asociación espacial de la distribución de los tipos de hogares con los indicadores estadísticos Gl obal M oran I y Local M oran I12, que miden el nivel de autocorrelación espacial a escala global y local respectivamente. Los val ores siguen una distribución similar al coeficiente de correlación de Pearson, oscilan entre -1 (autocorrelación negativa perfecta) a 1 (autocorrelación positiva perfecta). Un valor de cero o próximo a cero indica un patrón espacial aleatorio.

Las unidades espaciales de análisis son la NUTS 3 definidas por Eurostat para el censo de 2011.

La formulación matemática del indicador Global Moran I, es la siguiente(Moreno y Vayá 2000):

$$
I=\frac{N \cdot \sum_{i=1}^{N} \sum_{j=1}^{N} w_{i j} \cdot\left(x_{i}-\bar{x}\right) \cdot\left(x_{j}-\bar{x}\right)}{S_{o} \cdot \sum_{i=1}^{N}\left(x_{i}-\bar{x}\right)^{2}} \quad i \neq j
$$

Donde tenemos que $\mathbf{x}_{i}$ es el valor de la variable cuantitativa $\mathbf{x}$ en la región NUTS $3 \mathbf{i} ; \overline{\boldsymbol{x}}$ es el valor de la media de NUTS 3; $\mathbf{w}_{\mathrm{ij}}$, representa los pesos de la matriz $\mathbf{W}$; $\mathbf{N}$ es el tamaño de la muestra (número de NUTS 3) y $\boldsymbol{S}_{0}=\sum_{i} \sum_{j} w_{i j}$, la suma de los pesos.

Este indicador ofrece una visión del grado y tipo de asociación espacial de cada tipo de hogar. Con su cálculo se puede realizar un test de autocorrelación global, en el que la hipótesis nula $\left(\mathrm{H}_{0}\right)$ es la independencia espacial de la variable (los valores de una variable no dependen de los de sus vecinos): se contrasta si los valores de la distribución de las estructuras de hogares en una NUTS 3 son independientes de los

10 En el desarrollo del artículo se han utilizado los programas SPSS v23.0 para el análisis estadístico multivariante y GeoDA para el cálculo de los indicadores de análisis espacial.

11 La denominación rook procede de los movimientos de la torre en el juego de ajedrez.

12. Una explicación detallada de esta metodología puede verse en M oreno y Vayá 2000. 
valores de sus vecinas. Existen varias alternativas para estimar la probabilidad de que la distribución de los datos sea aleatoria (Leung, Mei y Zhang 2003), en este trabajo utilizaremos una aproximación al valor del Global Moran I a partir de una permutación aleatoria (en concreto 999 permutaciones, metodología que tiene asociada una probabilidad ( $p$-value) de $0,001^{13}$ ).

En el segundo tipo de autocorrelación espacial analizada, la local, se ha calculado con el estadístico Local Moran I. La formulación matemática de este indicador es, dada una unidad geográfica NUTS 3;, la siguiente (Anselin 1995; Moreno y Vayá 2000):

$$
I_{i}=\frac{z_{i}}{\sum_{i} z_{i}^{2} / N} \sum_{j \in J_{i}} w_{i j} z_{j}
$$

Donde $z_{i}$ es el valor de la NUTS $3_{i}$ de la variable normalizada y $J_{i}$ el conjunto de NUTS 3 vecinas a la NUTS 3. Los elementos de la matriz de pesos son, como en el caso del indicador comentado anteriormente, $\mathbf{w}_{\mathrm{ij}}$.

Hay una última consideración importante a tener en cuenta aquí y que atañe a ambos indicadores. Es el aspecto relacionado con la tipología de autocorrelación espacial que se establece a escala local con los valores calculados. Tenemos que esta metodología permite determinar la autocorrelación espacial positiva (en nuestro caso, regiones NUTS 3 donde se observa un valor alto de una tipología de hogares rodeado de áreas NUTS 3 con un valor también al to de las mismas formas; o bien valores bajos rodeados de val ores bajos) y la autocorrelación espacial negativa (valores al tos de un tipo de hogar rodeados de bajos del mismo, o bien a la inversa). Así, una autocorrelación espacial positiva indica la presencia de conglomerados (clústeres) de valores similares en el territorio y es, sin duda, una información que nos ayuda a localizar patrones espaciales de las estructuras de hogares. Por el contrario, la autocorrelación espacial negativa indica la existencia de valores singulares o atípicos de una estructura de hogares en un territorio.

La segunda de las técnicas estadísticas aplicadas es el análisis factorial o de componentes principales (Bizquerra 1989), que se aplica en esteestudio con el objetivo de reducir la información original (30 variantes de tipos de hogares) a una serie de factores que faciliten una interpretación más sencilla de la heterogeneidad territorial de las estructuras de hogares a escala NUTS 3. Los factores obtenidos representan las variables originales con una pérdida mínima de información y pueden darnos una nueva interpretación de las relaciones entre las variables originales. Para realizar el análisis factorial sobre nuestros datos regionales hemos estimado la matriz de correlaciones de las 30 variables, extrayendo posteriormente los factores cuyos valores propios eran superiores a 1. Estos han sido girados y representados gráficamente para facilitar su interpretación y darles a continuación nombre y, por último, han sido calculadas las puntuaciones factoriales correspondientes a cada factor y región NUTS 3.

\footnotetext{
13Esta metodología para el test de autocorrelación viene determinada por el uso que se ha hecho del paquete estadístico de análisis espacial $\mathrm{GeoDa}$, el cual permite seleccionar el número de permutaciones en función del grado de probabilidad que se desee dar al test.
} 
La tercera y última de las técnicas estadísticas empleadas es el análisis de conglomerados (clúster), que nos ha permitido, a partir delas puntuaciones factoriales obtenidas anteriormente, realizar la agrupación de las regiones NUTS 3 en áreas que disponen de una distribución equivalente o similar de la estructura de hogares. En este trabajo hemos utilizado un método jerárquico ascendente. En nuestro caso se ha empleado la distancia euclidiana al cuadrado, la distancia entre grupos se ha obtenido con el método de Ward (Bizquerra 1989).

\section{Resultados}

\section{Las estructuras de hogares a escala nacional en Europa}

Los resultados que proporcionan a escala nacional la ronda censal de 2010 en Europa confirman las importantes diferencias que existen en la estructura de hogares entre el norte y sur de Europa (Laslett 1983; Heady et al. 2010). La inclusión de los países del Este en la información proporcionada por Eurostat permite además dibujar una región de transición que participa de al gunas características de las dos áreas anteriormente señaladas, pero que no configura en sí misma una región homogénea por su elevada heterogeneidad interna (tabla 3) (Van Winkle 2018).

La población europea vive mayoritariamente en hogares privados. Las diferencias entre países son escasas, con la excepción destacada de Suecia en la que un significativo 5,1 por ciento de su población reside en alojamientos colectivos, fundamentalmente residencias de la tercera edad, mientras que en el conjunto europeo esta categoría es residual y apenas supone el 1,4 por ciento.

La población que no vive en un núcleo familiar registra una elevada dispersión entre países. Los valores más el evados se concentran en los países del norte de Europa y una selección de países del Este, encabezados por los países bálticos, frente al familiarismo que caracteriza el sur europeo, las distancias aquí no son tan importantes por la ponderación que introduce la población. La concentración de la población en hogares familiares es especialmente intensa en el área de influencia mediterránea. El verdadero contraste norte-sur se hace más evidente cuando, dentro de las formas no familiares, se consideran solo los hogares unipersonales. Este tipo de hogar se sitúa en el centro y norte de Europa sistemáticamente en valores superiores al 15 por ciento de la población duplicando los valores que ofrecen las regiones de la Europa mediterránea.

La proporción de personas que residen en hogares multipersonales (unidades domésticas sin núcleo familiar) muestra una geografía más compleja. Los países integrantes de la antigua Checoslovaquia presentan, por ejemplo, la proporción más elevada de este tipo de hogares, doblando la media europea. En términos generales, la jerarquía de la población que habita en hogares multipersonales está encabezada por países del Este y el Reino Unido e Irlanda. 
Tabla 3. Distribución de la población europea según el tipo de hogar en el que reside, Europa circa 2011

\begin{tabular}{|c|c|c|c|c|c|c|}
\hline País & 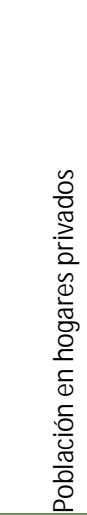 & 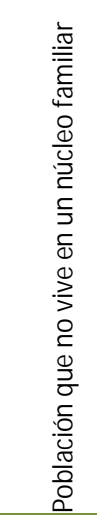 & 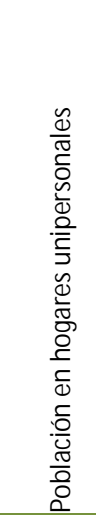 & 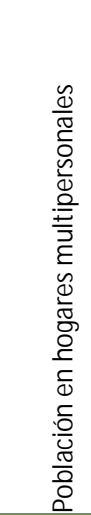 & 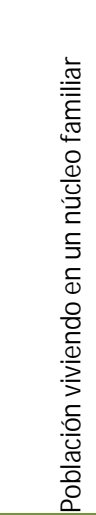 & 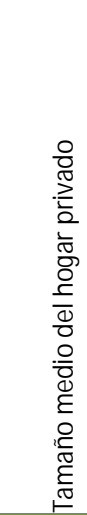 \\
\hline Austria & 98,5 & 20,1 & 15,8 & 4,4 & 78,4 & 2,27 \\
\hline Bélgica & 98,8 & 17,4 & 14,6 & 2,8 & 81,3 & 2,30 \\
\hline Bulgaria & 99,1 & 20,3 & 12,6 & 7,7 & 78,8 & 2,43 \\
\hline Suiza (1) & 100,0 & 21,3 & 19,1 & 2,1 & 76,4 & 2,20 \\
\hline Chipre & 99,5 & 13,7 & 7,5 & 6,2 & 85,8 & 2,76 \\
\hline República Checa & 98,0 & 26,4 & 13,5 & 12,9 & 71,6 & 2,34 \\
\hline Alemania & 98,5 & 21,2 & 17,2 & 4,1 & 76,8 & 2,14 \\
\hline Dinamarca & 98,5 & 22,0 & 17,0 & 5,0 & 76,6 & 2,17 \\
\hline Estonia & 98,8 & 22,6 & 18,5 & 4,1 & 76,2 & 2,13 \\
\hline Grecia & 97,7 & 15,7 & 9,8 & 5,9 & 81,9 & 2,55 \\
\hline España & 99,5 & 14,6 & 9,0 & 5,6 & 84,9 & 2,58 \\
\hline Francia & 97,7 & 18,3 & 14,5 & 3,8 & 79,4 & 2,27 \\
\hline Croacia & 99,1 & 13,4 & 8,7 & 4,6 & 85,7 & 2,80 \\
\hline Hungría & 97,6 & 19,3 & 13,3 & 6,0 & 78,3 & 2,36 \\
\hline Irlanda & 98,8 & 17,6 & 8,5 & 9,1 & 78,6 & 2,74 \\
\hline Islandia & 97,4 & 17,2 & 11,7 & 5,5 & 80,2 & 2,40 \\
\hline Italia & 99,4 & 17,4 & 12,1 & 5,3 & 82,0 & 2,40 \\
\hline Liechtenstein & 99,3 & 18,3 & 14,6 & 3,7 & 81,0 & 2,32 \\
\hline Lituania & 99,2 & 18,0 & 13,2 & 4,8 & 81,2 & 2,38 \\
\hline Luxemburgo & 98,6 & 16,2 & 11,8 & 4,4 & 82,4 & 2,41 \\
\hline Letonia & 98,7 & 21,0 & 14,3 & 6,7 & 77,8 & 2,38 \\
\hline Malta & 97,9 & 11,6 & 8,3 & 3,3 & 86,3 & 2,67 \\
\hline Países Bajos & 98,7 & 17,7 & 16,3 & 1,5 & 80,9 & 2,21 \\
\hline Noruega & 98,9 & 19,7 & 17,7 & 2,1 & 79,2 & 2,22 \\
\hline Polonia & 99,4 & 13,7 & 8,5 & 5,2 & 85,7 & 2,82 \\
\hline Portugal & 98,8 & 12,3 & 8,2 & 4,1 & 86,5 & 2,58 \\
\hline Rumanía & 99,0 & 17,4 & 9,6 & 7,8 & 81,6 & 2,67 \\
\hline Suecia & 94,9 & 19,6 & 15,3 & 4,3 & 75,3 & 2,25 \\
\hline Eslovenia & 98,4 & 17,2 & 13,0 & 4,2 & 81,1 & 2,48 \\
\hline Eslovaquia & 96,6 & 20,1 & 8,4 & 11,6 & 75,7 & 2,90 \\
\hline Reino Unido & 98,2 & 19,2 & 12,8 & 6,4 & 79,1 & 2,35 \\
\hline Europa & 98,6 & 18,2 & 13,0 & 5,2 & 80,3 & 2,37 \\
\hline Media & 98,5 & 18,1 & 12,8 & 5,3 & 80,2 & 2,4 \\
\hline Mediana & 98,7 & 18,0 & 13,0 & 4,8 & 80,2 & 2,4 \\
\hline Mínimo & 94,9 & 11,6 & 7,5 & 1,5 & 71,6 & 2,1 \\
\hline Máximo & 100,0 & 26,4 & 19,1 & 12,9 & 86,5 & 2,9 \\
\hline Coeficiente de variación & & $17,6 \%$ & $26,4 \%$ & $46,3 \%$ & $4,5 \%$ & $8,8 \%$ \\
\hline
\end{tabular}

Fuente: Elaboración propia a partir de los datos obtenidos en Censushub2:

https://ec.europa.eu/CensusHub2/query.do?step=selectHyperCube\&qhc=false

(1) Población de más de 15 años que reside en hogares privados. 
Este resultado no puede ser interpretado con nuestros actuales conocimientos, pero podría estar asociado en el caso de estos dos últimos países a efectos de la inmigración extranjera, más propicia a este tipo de estructuras en las primeras fases del proceso migratorio en las regiones de acogida14. En todo caso, estas formas complejas de hogares son poco representativas en la mayoría de los países y muestran el grado más elevado de dispersión entre las formas de convivencia que aparecen en la tabla 3.

La forma predominante de residencia en toda Europa sigue siendo la población que vive en núcleos familiares representados por hogares conyugales con o sin hijos y sus formas derivadas, las familias monoparentales, o equiparables, las uniones consensuales. Estos valores se sitúan entre el 71,6 y el 86,5 por ciento. Los países del sur de Europa y Polonia encabezan esta jerarquía, en todos ellos la población que reside en este tipo de hogares se eleva hasta el 85 por ciento. Los países nórdicos muestran, en general, valores más reducidos, 10 puntos porcentuales por debajo de los países mediterráneos. El valor del coeficiente de variación en este caso es realmente bajo (4,5 por ciento), prueba de unos valores homogéneos entre los países de Europa.

En resumen, los hogares unipersonales y multipersonales, ambos pertenecientes a la categoría de hogares no familiares, son las estructuras que presentan una mayor dispersión entre paises en el conjunto de Europa, con coeficientes de variación del 26,4 y 46,3 por ciento respectivamente.

\section{La distribución geográfica de los tipos de hogares en Europa a escala regional}

La introducción de la escala de observación más pequeña, correspondiente a las regiones NUTS 3 de Eurostat, nos permite confeccionar una imagen más precisa de la distribución espacial de las estructuras de hogares en Europa y responder a la pregunta sobre la existencia de variaciones territoriales ocultas por las uniformidades que imponen los estudios basados en agregados nacionales. Para ello vamos a emplear los principales indicadores de estadística descriptiva que afectan a 30 variantes de tipos de hogar en las 1.340 unidades finalmente analizadas (tabla 4). Someteremos a un escrutinio individual a cada uno de los países, para cotejar si la distribución territorial interna de estas estructuras sigue una pauta geográfica uniforme o se registran diferencias significativas entre las regiones de un mismo país (tabla 5 y figura 1). Los valores que se presentan en las tablas a partir de aquí no están ponderados por población. Es decir, los indicadores solo tienen en cuenta la proporción que representa cada tipo de hogar y no la población que reside en ellos.

Los hogares no familiares, una de las formas emergentes de estructuras familiares según la STD, presenta un bajo coeficiente de variación (19,5 por ciento), pero un gran recorrido estadístico entre el conjunto de las regiones europeas: El valor

14 Así lo indican para el caso español los análisis desarrollados por Domingo y Bayona 2010. 
de la mediana situado en 3.383 hogares por cada 10.000 hogares es una señal de los importantes contrastes territorial es que sugieren estos indicadores. En un 25 por ciento de las regiones europeas este val or se sitúa por encima del 37 por ciento del conjunto de hogares, una cantidad nada desdeñable.

Las diferentes variantes de hogares unipersonales exhiben también elevados niveles de dispersión geográfica. La proporción que representa el conjunto de este tipo de hogares oscila entre un mínimo de 1.223 y un máximo de 5.290 por cada 10.000 hogares, cifra esta última correspondiente a la región de Oslo en Noruega. Los hogares unipersonales de jóvenes ostentan significativos coeficientes de variación cercanos al 40 por ciento. Sin embargo, las mujeres jóvenes que viven solas constituyen uno de los modelos con mayor variabilidad espacial y una de las estructuras de hogares más innovadoras en el contexto de Europa.

Los tipos de hogar que cuentan con la máxima dispersión territorial en Europa son los hogares con dos o más familias y los hogares multipersonales (con coeficientes de variación de 117 y 64 por ciento respectivamente), como ya indicaban los parámetros estadísticos que ofrecían los datos nacionales expuestos en la tabla 4. Ahora, los indicadores obtenidos en una escala más pequeña corroboran la singularidad territorial de este tipo de estructura de hogares, de los que no hay que olvidar tampoco su escasa representación estadística.

Todas las formas familiares integradas por parejas casadas, sin hijos o con hijos manifiestan bajos coeficientes de variación, con la excepción de aquellas en las que los hijos mayores permanecen en el hogar familiar hasta edades avanzadas. Esta última forma de familia nuclear alcanza uno de los coeficientes de dispersión territorial más elevados entre las formas familiares analizadas y, por tanto, prueba de una localización concreta en el espacio mediterráneo europeo.

Las uniones consensuales expresan, como era de esperar, un mayor grado de dispersión geográfica en función de su localización significativa en un escaso número de países.

Finalmente, los hogares monoparentales encabezados por mujeres con hijos pequeños, los más representativos en este tipo de estructuras, se caracterizan por una menor dispersión estadística muy cercana a la de las parejas con hijos pequeños. No es de extrañar este resultado puesto que la mayoría de las familias monoparentales se constituyen, por lo general, tras un divorcio o una ruptura de una unión consensual. Por el contrario, las familias monoparentales con hijos mayores de 25 años, revelan una acusada concentración territorial y coeficientes de variación cercanos o superiores al 60 por ciento (tabla 4). 
Tabla 4. Indicadores estadísticos según los tipos de hogares en Europa, circa 2011 (por 10.000 hogares)

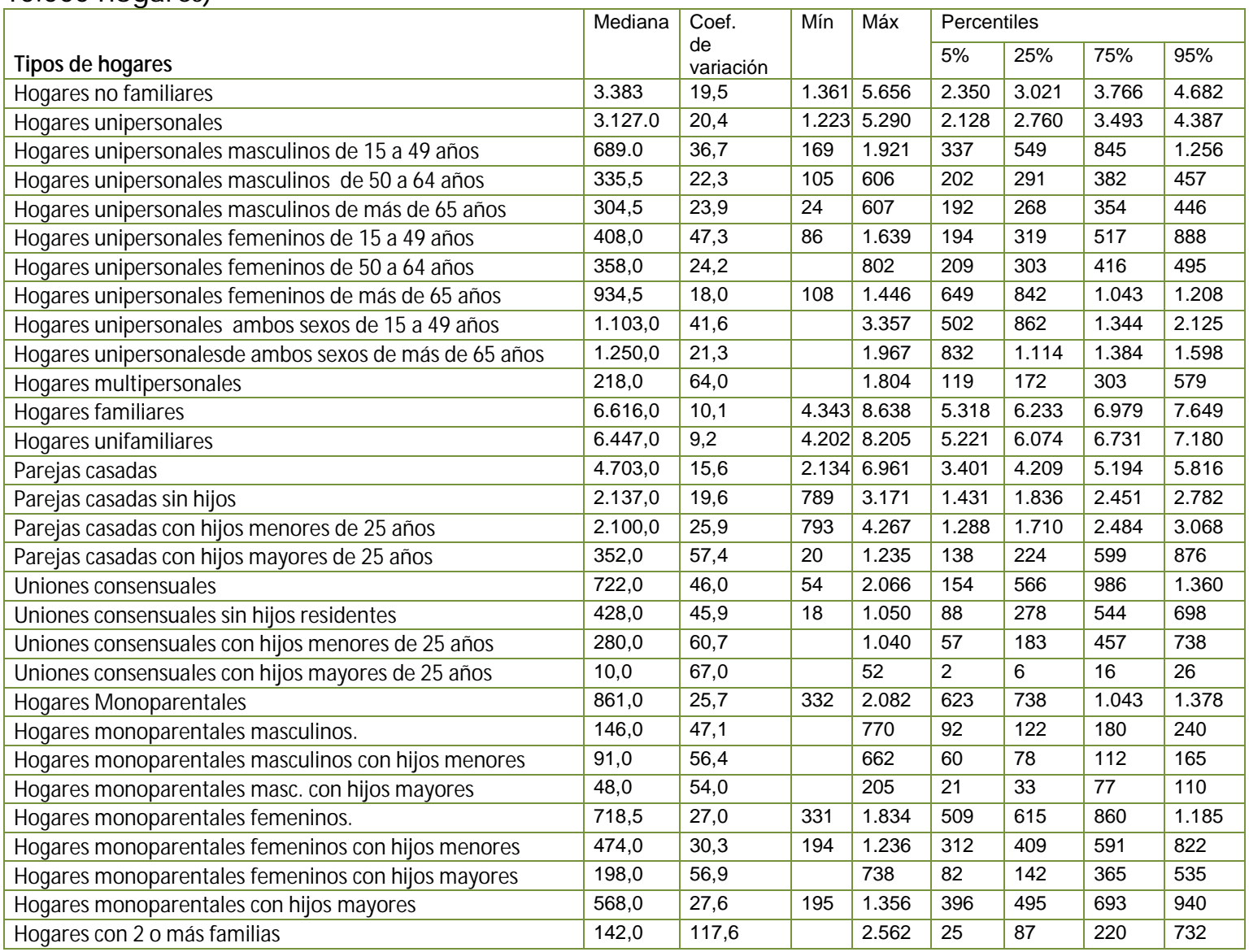

Fuente: Elaboración propia a partir de los datos obtenidos en Censushub2:

https://ec.europa.eu/CensusHub2/query.do? step=selectHyperCube\&qhc=false

En la figura 1 se representan en un diagrama de cajas los principales estadísticos (mínimo, media, mediana, máximo, cuartilesy valores atípicos) de 12 tipos de hogares para el conjunto de las áreas NUTS 3 de cada país. Es por tanto una medida gráfica resumen del grado de dispersión entre regiones de un mismo país y entre países para cada una de las estructuras de hogares consideradas.

Estos resultados corroboran dos tesis importantes en relación con la geografía de los tipos de hogares en Europa. La primera de ellas es que existen diferencias entre países en la intensidad y estructura espacial de las estructuras de hogares y que estas no afectan por igual a todos los tipos analizados. La variabilidad geográfica de los hogares familiares y las parejas casadas es pequeña y con apenas diferencias entre países, mientras que otras formas más modernas, como los hogares unipersonales de jóvenes, las parejas casadas con hijos mayores, las uniones consensual es y las familias monoparentales de diverso tipo muestran una elevada variabilidad tanto interna como entre países. Existen por lo tanto especificidades nacionales lejos de una pretendida convergencia europea (Kuijsten 1996; Fokkema y Liefbroer 2008; Sobotka y Toulemon 2008; Potârca et al. 2013). 


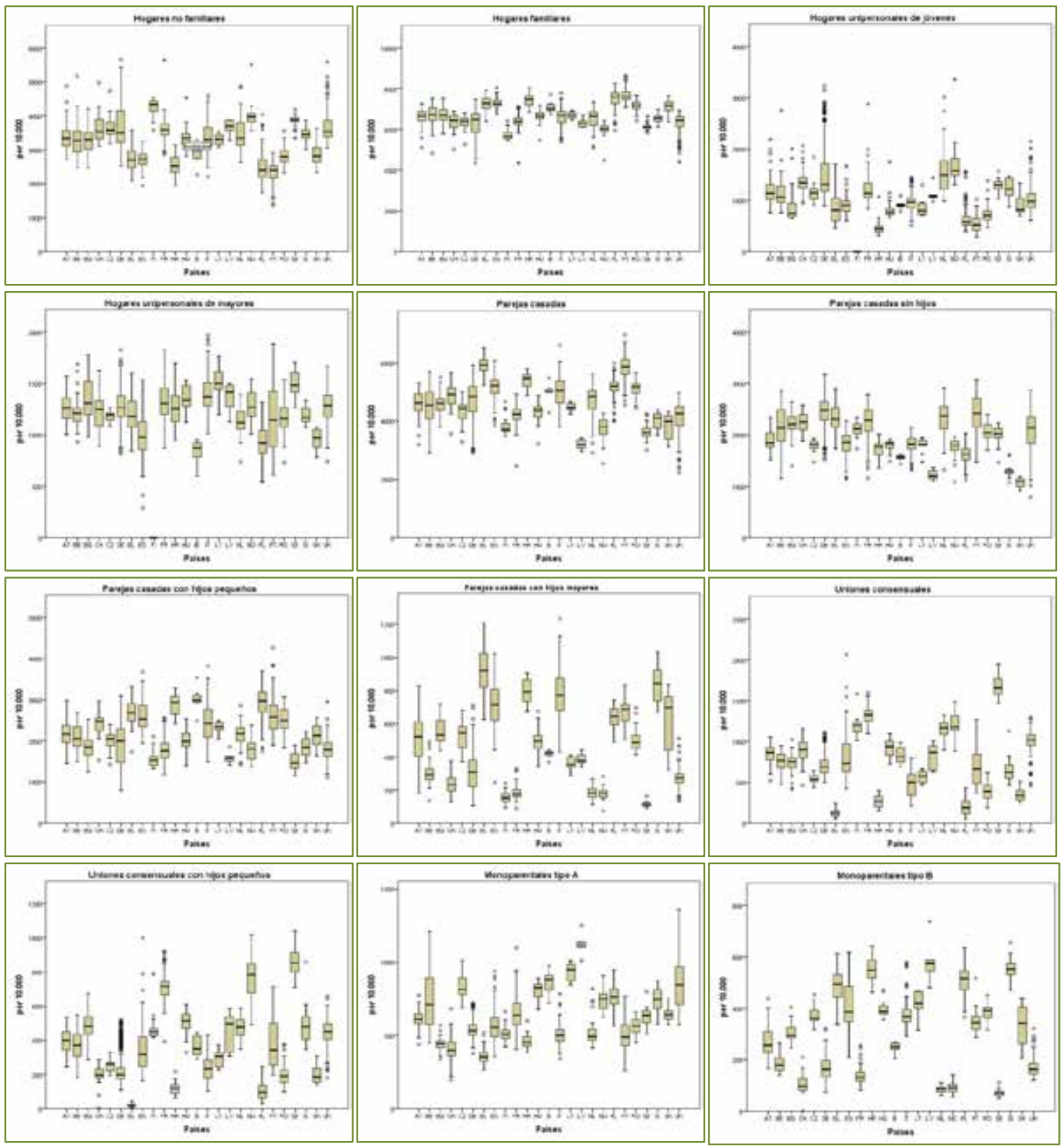

Figura1. Indicadores estadísticos de los tipos de hogares por países en Europa a escala NUTS3, circa 2011

Fuente: Elaboración propia a partir de los datos de Eurostat (Censushub2)

https://ec.europa.eu/CensusHub2/query.do?step=selectHyperCube\&qhc=false 
Tabla 5. Indicadores estadísticos regionales por países de los tipos de hogares, Europa circa 2011

\begin{tabular}{|c|c|c|c|c|c|c|c|c|c|c|c|c|c|}
\hline \multicolumn{2}{|l|}{ País } & 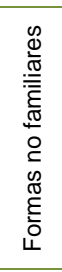 & 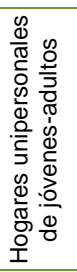 & 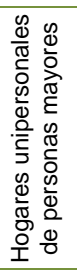 & 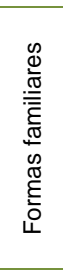 & $\begin{array}{l}0 \\
\frac{\pi}{0} \\
0 \\
0 \\
0 \\
0 \\
0 \\
\frac{\pi}{0} \\
\frac{\pi}{01} \\
\frac{\pi}{0} \\
0\end{array}$ & 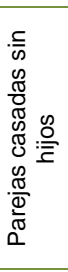 & 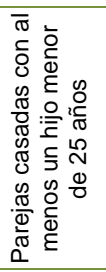 & 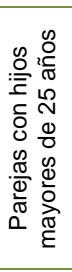 & 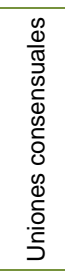 & 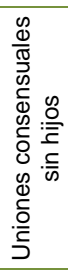 & 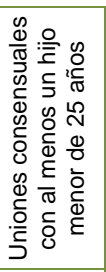 & 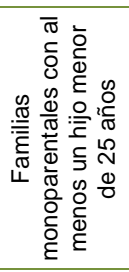 \\
\hline \multirow[t]{2}{*}{ Austria } & Media & 34,3 & 12,2 & 12,6 & 65,7 & 45,7 & 18,9 & 21,6 & 5,2 & 8,4 & 4,2 & 4,0 & 6,1 \\
\hline & $\mathrm{CV}$ & 14,2 & 26,9 & 11,0 & 7,4 & 10,5 & 10,9 & 16,2 & 28,7 & 13,7 & 17,0 & 19,1 & 10,9 \\
\hline \multirow[t]{2}{*}{ Bélgica } & Media & 33,1 & 11,6 & 12,2 & 66,9 & 45,4 & 21,6 & 20,8 & 3,0 & 7,6 & 3,8 & 3,7 & 7,4 \\
\hline & $\mathrm{CV}$ & 14,9 & 29,8 & 11,5 & 7,4 & 13,9 & 17,0 & 15,1 & 22,1 & 14,6 & 12,2 & 22,5 & 26,0 \\
\hline \multirow[t]{2}{*}{ Bulgaria } & Media & 33,2 & 8,7 & 13,5 & 66,8 & 45,9 & 22,0 & 18,4 & 5,6 & 7,3 & 2,4 & 4,8 & 4,4 \\
\hline & $\mathrm{CV}$ & 12,2 & 38,5 & 16,4 & 6,1 & 8,6 & 11,1 & 16,6 & 13,2 & 18,8 & 28,2 & 19,5 & 10,5 \\
\hline \multirow[t]{2}{*}{ Suiza } & Media & 36,4 & 14,0 & 12,2 & 63,6 & 48,8 & 22,4 & 24,1 & 2,3 & 8,8 & 6,7 & 2,0 & 4,1 \\
\hline & $\mathrm{CV}$ & 11,6 & 19,1 & 14,5 & 6,6 & 8,9 & 8,9 & 12,1 & 28,1 & 17,5 & 20,8 & 30,2 & 26,1 \\
\hline \multirow[t]{2}{*}{ Rep. Checa } & Media & 36,8 & 11,7 & 11,8 & 63,2 & 43,1 & 17,9 & 20,0 & 5,2 & 5,4 & 2,7 & 2,6 & 8,3 \\
\hline & $\mathrm{CV}$ & 11,1 & 19,9 & 4,0 & 6,4 & 10,9 & 6,6 & 13,9 & 19,4 & 11,5 & 14,5 & 15,8 & 11,1 \\
\hline \multirow[t]{2}{*}{ Alemania } & Media & 37,2 & 15,0 & 12,8 & 62,8 & 46,8 & 24,6 & 19,1 & 3,1 & 7,1 & 4,6 & 2,4 & 5,4 \\
\hline & $\mathrm{CV}$ & 18,2 & 31,5 & 12,6 & 10,8 & 14,2 & 12,2 & 26,7 & 34,8 & 16,9 & 14,4 & 41,3 & 10,7 \\
\hline \multirow[t]{2}{*}{ Dinamarca } & Media & 39,6 & 13,2 & 14,7 & 60,4 & 40,0 & 21,8 & 17,7 & 0,5 & 10,9 & 6,2 & 4,7 & 6,2 \\
\hline & $\mathrm{CV}$ & 14,5 & 32,7 & 12,2 & 9,5 & 17,0 & 19,4 & 18,7 & 23,3 & 14,2 & 22,6 & 8,0 & 11,9 \\
\hline \multirow[t]{2}{*}{ Estonia } & Media & 41,7 & 13,6 & 15,7 & 58,3 & 30,6 & 15,3 & 13,0 & 2,4 & 13,3 & 5,3 & 7,7 & 8,3 \\
\hline & $\mathrm{CV}$ & 2,1 & 20,8 & 12,3 & 1,5 & 8,0 & 12,8 & 7,1 & 15,5 & 25,2 & 21,1 & 29,5 & 6,9 \\
\hline \multirow[t]{2}{*}{ Grecia } & Media & 27,4 & 8,5 & 12,0 & 72,6 & 59,1 & 23,2 & 26,8 & 9,0 & 1,3 & 1,1 & 0,2 & 3,6 \\
\hline & $\mathrm{CV}$ & 12,4 & 36,0 & 14,8 & 4,7 & 5,4 & 11,6 & 11,4 & 16,0 & 37,0 & 37,9 & 47,1 & 16,3 \\
\hline \multirow[t]{2}{*}{ España } & Media & 27,0 & 9,1 & 9,7 & 73,0 & 51,5 & 18,1 & 26,3 & 7,1 & 8,3 & 4,4 & 3,6 & 5,7 \\
\hline & $\mathrm{CV}$ & 10,3 & 20,4 & 24,2 & 3,8 & 9,5 & 14,7 & 16,2 & 20,2 & 38,2 & 39,7 & 44,5 & 21,7 \\
\hline \multirow[t]{2}{*}{ Finlandia } & Media & 42,5 & & & 57,5 & 38,4 & 21,0 & 15,8 & 1,5 & 11,9 & 7,1 & 4,7 & 5,1 \\
\hline & $\mathrm{CV}$ & 6,3 & & & 4,7 & 8,6 & 7,2 & 14,8 & 23,7 & 10,0 & 9,6 & 18,0 & 11,2 \\
\hline Francia & Media & 35,9 & 12,4 & 13,2 & 64,1 & 42,2 & 22,5 & 17,8 & 1,8 & 13,3 & 6,1 & 7,1 & 6,6 \\
\hline & $\mathrm{CV}$ & 9,8 & 23,2 & 14,4 & 5,5 & 7,7 & 14,0 & 15,9 & 20,0 & 7,0 & 7,2 & 11,3 & 18,5 \\
\hline Croacia & Media & 25,5 & 4,8 & 12,7 & 74,5 & 54,0 & 17,2 & 28,9 & 8,0 & 2,6 & 1,3 & 1,2 & 4,6 \\
\hline & $\mathrm{CV}$ & 12,3 & 34,1 & 15,3 & 4,2 & 4,8 & 9,8 & 9,2 & 9,2 & 29,1 & 33,1 & 33,1 & 11,1 \\
\hline Hungría & Media & 33,6 & 8,5 & 13,6 & 66,4 & 43,1 & 17,9 & 20,2 & 5,0 & 9,2 & 3,8 & 5,1 & 8,1 \\
\hline & $\mathrm{CV}$ & 10,9 & 29,0 & 8,7 & 5,5 & 8,7 & 6,3 & 13,2 & 15,1 & 11,3 & 15,6 & 14,6 & 7,7 \\
\hline Irlanda & Media & 29,0 & 9,2 & 8,4 & 71,0 & 49,9 & 15,6 & 30,1 & 4,2 & 8,3 & 4,6 & 3,7 & 8,6 \\
\hline & $\mathrm{CV}$ & 10,8 & 9,2 & 13,9 & 4,4 & 6,6 & 3,8 & 9,6 & 5,5 & 13,1 & 19,8 & 16,4 & 9,3 \\
\hline Islandia & Media & 33,6 & 13,7 & 9,6 & 59,4 & 39,3 & 15,3 & 21,9 & 2,2 & 10,2 & 1,7 & 8,4 & 8,7 \\
\hline & $\mathrm{CV}$ & 12,6 & 26,5 & 2,0 & 6,6 & 11,1 & 17,7 & 7,2 & 3,9 & 13,0 & 2,9 & 14,7 & 18,1 \\
\hline Italia & Media & 33,8 & 9,7 & 14,1 & 66,2 & 50,3 & 18,1 & 24,4 & 7,8 & 4,8 & 2,2 & 2,4 & 5,1 \\
\hline & $\mathrm{CV}$ & 12,4 & 18,2 & 13,6 & 6,3 & 10,2 & 9,4 & 18,9 & 18,7 & 30,8 & 39,1 & 27,4 & 13,9 \\
\hline Lituania & Media & 33,0 & 8,5 & 15,0 & 67,0 & 44,8 & 17,9 & 23,3 & 3,6 & 5,7 & 2,5 & 2,9 & 9,3 \\
\hline & $\mathrm{CV}$ & 5,0 & 21,1 & 11,2 & 2,5 & 3,4 & 7,9 & 6,0 & 10,9 & 12,9 & 9,7 & 18,0 & 6,5 \\
\hline Letonia & Media & 36,7 & 11,2 & 13,7 & 63,3 & 32,0 & 12,2 & 15,9 & 3,8 & 8,3 & 3,2 & 4,6 & 11,2 \\
\hline & $\mathrm{CV}$ & 6,3 & 14,3 & 10,7 & 3,6 & 5,4 & 8,3 & 9,3 & 9,4 & 19,0 & 12,3 & 25,1 & 7,0 \\
\hline Malta & Media & 26,8 & 7,0 & 10,5 & 73,2 & 59,7 & 19,2 & 33,1 & 7,4 & 2,1 & 1,2 & 0,8 & 5,0 \\
\hline & $\mathrm{CV}$ & 10,3 & 11,2 & 17,1 & 3,7 & 1,1 & 0,2 & 4,4 & 10,2 & 43,6 & 39,1 & 52,3 & 37,2 \\
\hline Países & Media & 34,8 & 15,6 & 11,4 & 65,2 & 46,5 & 23,2 & 21,5 & 1,8 & 11,5 & 6,7 & 4,7 & 5,2 \\
\hline Bajos & $\mathrm{CV}$ & 14,3 & 29,6 & 11,5 & 7,7 & 12,6 & 14,7 & 13,9 & 20,3 & 8,4 & 9,1 & 12,8 & 18,1 \\
\hline Noruega & Media & 40,4 & 17,2 & 12,8 & 59,6 & 37,2 & 17,4 & 17,9 & 1,8 & 12,1 & 4,4 & 7,6 & 7,4 \\
\hline & $\mathrm{CV}$ & 10,0 & 26,5 & 12,3 & 6,8 & 11,7 & 12,5 & 16,2 & 23,6 & 13,0 & 16,1 & 18,6 & 9,6 \\
\hline Polonia & Media & 25,1 & 6,8 & 9,3 & 74,9 & 51,4 & 16,2 & 28,8 & 6,4 & 2,0 & 0,9 & 1,0 & 7,7 \\
\hline & $\mathrm{CV}$ & 19,9 & 40,7 & 17,5 & 6,7 & 7,7 & 11,1 & 15,0 & 9,2 & 50,3 & 61,9 & 50,5 & 10,0 \\
\hline Portugal & Media & 22,9 & 5,4 & 11,5 & 77,1 & 58,0 & 24,2 & 27,1 & 6,7 & 7,0 & 3,0 & 3,8 & 5,1 \\
\hline & $\mathrm{CV}$ & 17,4 & 32,6 & 28,8 & 5,2 & 9,6 & 16,6 & 21,5 & 12,1 & 37,8 & 35,8 & 40,4 & 23,9 \\
\hline Rumania & Media & 28,1 & 7,3 & 11,7 & 71,9 & 51,0 & 20,6 & 25,3 & 5,0 & 4,0 & 1,8 & 2,0 & 5,6 \\
\hline & $\mathrm{CV}$ & 9,3 & 23,8 & 13,2 & 3,6 & 6,0 & 8,1 & 11,9 & 12,5 & 27,1 & 29,9 & 33,2 & 9,3 \\
\hline Suecia & Media & 38,6 & 12,9 & 15,0 & 61,4 & 36,3 & 20,1 & 15,1 & 1,1 & 16,7 & 8,0 & 8,6 & 6,2 \\
\hline & $\mathrm{CV}$ & 4,9 & 9,8 & 8,3 & 3,0 & 8,1 & 9,2 & 14,6 & 14,7 & 7,7 & 6,8 & 9,4 & 11,3 \\
\hline Eslovenia & Media & 34,6 & 12,5 & 11,9 & 65,4 & 40,1 & 13,1 & 18,5 & 8,4 & 6,7 & 1,3 & 5,0 & 7,4 \\
\hline & $\mathrm{CV}$ & 6,7 & 16,0 & 6,8 & 3,5 & 7,8 & 11,9 & 13,3 & 14,4 & 26,5 & 25,3 & 27,0 & 13,3 \\
\hline Eslovaquia & Media & 28,8 & 9,1 & 9,6 & 71,2 & 38,2 & 10,7 & 21,3 & 6,2 & 3,5 & 1,3 & 2,0 & 6,5 \\
\hline & $\mathrm{CV}$ & 13,6 & 23,3 & 11,1 & 5,5 & 12,6 & 9,4 & 14,7 & 31,9 & 24,7 & 28,0 & 29,1 & 8,3 \\
\hline Reino & Media & 36,8 & 10,4 & 12,9 & 63,2 & 41,3 & 20,6 & 17,9 & 2,8 & 10,0 & 5,4 & 4,5 & 8,5 \\
\hline Unido & $\mathrm{CV}$ & 12,2 & 25,6 & 13,6 & 7,1 & 13,4 & 19,6 & 15,4 & 19,7 & 14,1 & 17,8 & 18,5 & 19,4 \\
\hline Europa & Media & 34,2 & 11,6 & 12,3 & 65,8 & 46,7 & 21,3 & 21,2 & 4,2 & 7,6 & 4,1 & 3,4 & 6,1 \\
\hline & $\mathrm{CV}$ & 19,5 & 41,6 & 21,3 & 10,1 & 15,6 & 19,6 & 25,9 & 57,4 & 46,0 & 45,9 & 60,7 & 27,6 \\
\hline
\end{tabular}

Fuente: Elaboración propia a partir de los datos obtenidos en Censushub2:

https://ec.europa.eu/CensusHub2/query.do? step=selectHyperCube\&qhc=false 
La segunda es la existencia de una diversidad regional de los tipos de hogares en el interior de los países que no afecta por igual a la totalidad de las estructuras de hogares y de países considerados (tabla 5). Los mayores coeficientes de variación corresponden para la casi totalidad de los países europeos, a los hogares unipersonales dejóvenes y las uniones consensuales, las parejas casadas con hijos mayores de 25 años y las familias monoparentales, que muestran también una destacada dispersión, pero en rangos de menor intensidad y extensión geográfica.

Los datos empíricos respaldan, por tanto, la imagen de unas estructuras de hogares en Europa que constituyen un mosaico geográfico lejos de la imagen de convergencia estructural que auspiciaba la teoría de la Segunda Transición Demográfica. Los indicios de modernidad que representan los hogares unipersonales de jóvenes, las uniones consensuales y las familias monoparentales, conviven con adaptaciones de estructuras conyugales clásicas a las dificultades económicas: las parejas casadas con hijos mayores de 25 años vinculadas a la emancipación tardía. Ambos factores contribuyen al mosaico geográfico de los tipos de hogares en Europa.

En la figura 2 se representan diferentes mapas con la distribución geográfica de las estructuras de hogares en Europa a escala NUTS 3. La distribución se presenta por quintiles (grupos acumulados del 20 por ciento) correspondientes a cada tipo de hogar representado. Con este tipo de distribución estadística realizaremos una comparación individualizada de la distribución espacial para cada tipo de hogar.

Los hogares no familiares alcanzan su máxima expresión en las regiones NUTS 3 de los países nórdicos y bálticos, donde la práctica totalidad de esas áreas analizadas se sitúan en los Q4 y Q5. Por el contrario, la mayor parte de las provincias españolas, excepto ciertas áreas rurales del interior peninsular, Portugal, el sur de Italia, Croacia, Grecia, Rumanía y Polonia y una notable superficie de Irlanda se sitúan en los Q1 y Q2. El mapa de los hogares familiares es el inverso del registrado para los hogares no familiares (Figura 2).

Los hogares unipersonales de jóvenes tienen una presencia destacada en los países nórdicos, especialmente en el sur de Noruega y en diferentes núcleos urbanos de la Europa central y occidental donde se radican importantes centros universitarios. La formación y distribución geográfica de los hogares unipersonales de personas mayores parece responder a otras lógicas espaciales, son nuevamente abundantes en los países nórdicos y el conjunto de países bálticos, pero también es un tipo de hogar con presencia destacada en las áreas rurales de toda Europa vinculadas tanto a los procesos de despoblación rural como a ámbitos espacial es más restringidos de la costa francesa e italiana donde se retiran jubilados de los países del norte de Europa con un elevado poder adquisitivo.

La distribución geográfica de los hogares integrados por parejas casadas depende fundamentalmente del número y características de los hijos y, por tanto, de los niveles de fecundidad. Las parejas casadas tienen su máxima prevalencia en el centro y sur de España, conjunto de Portugal, el sur de Italia, Grecia y al gunas regiones de Polonia, todos ellas zonas geográficas que hemos asociado reiteradamente con el modelo familiar más tradicional. No así entre las parejas casadas sin hijos, las cuales 
tienen un reparto geográfico mucho más heterogéneo. Este tipo de forma familiar adquiere su máxima expresión en Alemania, especialmente en su región oriental, donde constituyen un área muy compacta y también en ciertos ámbitos rurales del interior de Portugal, Francia y, de forma más dispersa, en Reino Unido; en el extremo contrario, se encuentran, I rlanda, Polonia y el sur de España e Italia donde las parejas sin hijos tienen solo una presencia testimonial.

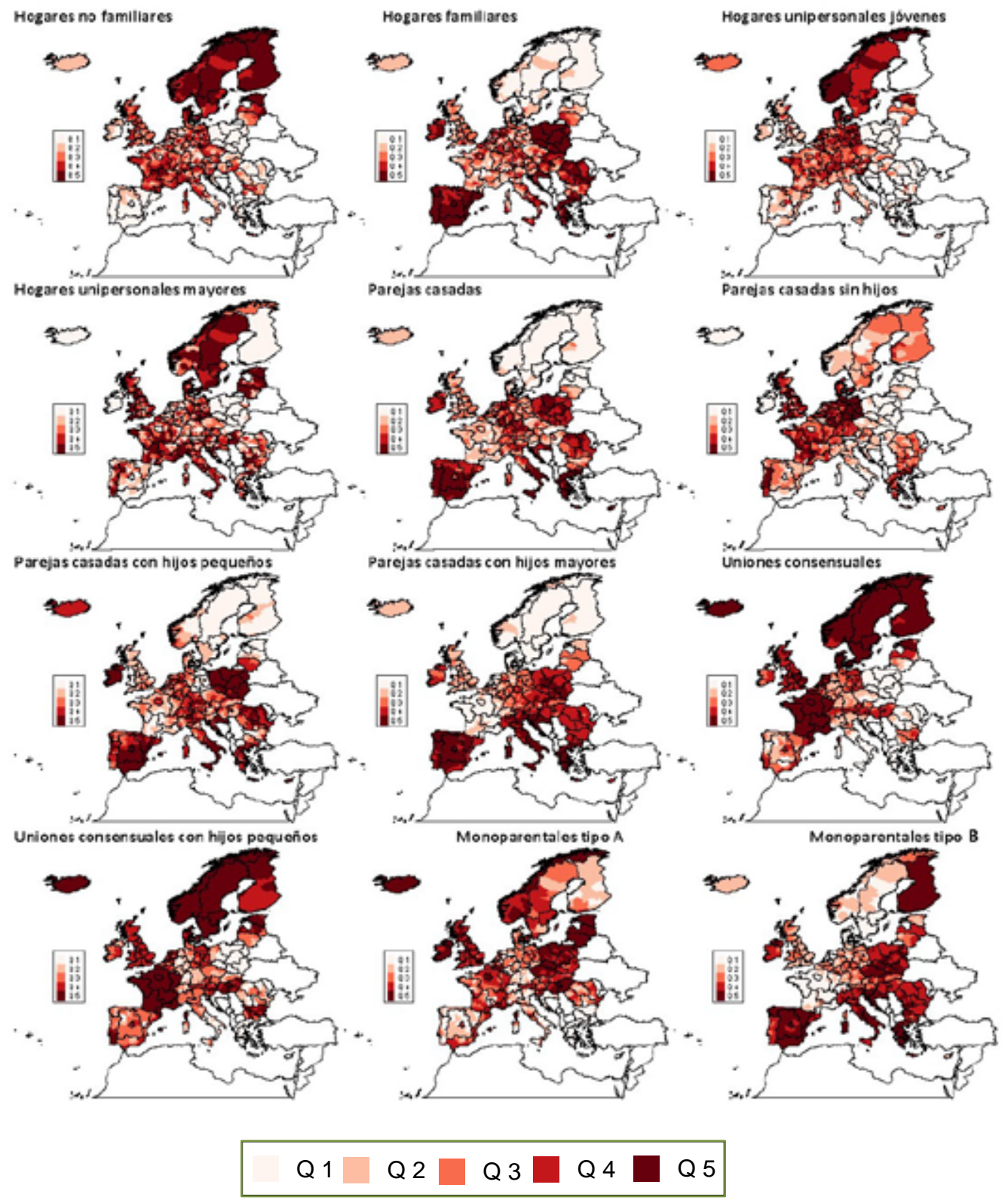

Figura 2. Distribución espacial de los tipos de hogares en Europa por NUTS3, circa 2011 Fuente: Elaboración propia a partir de los datos de Eurostat (Censushub2) https://ec.europa.eu/CensusHub2/query.do?step=selectHyperCube\&qhc=false

Los hogares integrados por parejas con hijos pequeños reproducen el esquema espacial del conjunto de parejas casadas. Sin embargo, el mapa de las parejas casadas con hijos mayores es el mapa de la emancipación tardía, uno de los distintivos actuales del sistema familiar característico del sur de Europa, siendo dominante en la mayoría de regiones de España, Portugal, Italia, Croacia y Grecia y en algunas regiones de 
Polonia, valores que contrastan profundamente con países limítrofes dela región como Francia, prueba palpable de la distribución heterogénea de los tipos de hogares en Europa, pero sobre todo de las intensas influencias de los contextos nacionales en las peculiares distribuciones geográficas de cierto tipo de estructuras de hogares.

Las uniones consensuales, estandarte de las formas modernas de unión conyugal, y fuertemente asociadas con la existencia de un sustrato legal einstitucional, se extienden por el conjunto de países que han desarrollado legislaciones favorables a esta forma de unión y cuyas estructuras sociales al ientan una emancipación temprana de los jóvenes: Francia, Países Bajos, Dinamarca y la Península Escandinava, Estonia e Islandia son ejemplos claros de concentración de este tipo de hogares. En el resto de países donde estas estructuras aparecen como es el caso de Reino Unido y España, las distribuciones espaciales son más complejas y están claramente vinculadas con regiones innovadoras en lo económico y/o social: se trata de áreas del sudeste de Inglaterra, entre ellas Londres, y algunas provincias españolas, como Barcelona, Gerona y las dos regiones insulares. El caso belga es extremadamente interesante porque muestra una nítida frontera entre la región valona, con comportamientos similares a Francia, y la región flamenca más cercana a los valores registrados en Alemania. Las uniones consensuales son anecdóticas en Italia, Grecia y Polonia. España, Portugal e Irlanda se diferencian de estos últimos países porque presentan diferencias intra-nacionales y continuidades trasnacionales.

La presencia de hogares monoparentales del tipo A (con hijos pequeños) es significativa en la práctica totalidad de los países del este de Europa donde las tasas de divorcio son las más elevadas del continente europeo, también en Noruega, Reino Unido (Wesling y Kane 1999) e I rlanda, en estos dos últimos países vinculados con la fecundidad en adolescentes solteras y, especialmente, en los países bálticos, donde se alcanzan los mayores valores de estos tipos de hogares. Mientras que los hogares monoparentales de tipo B (con hijos mayores) son formas más cercanas a las parejas casadas con hijos mayores y tienen una distribución espacial relacionada con formas más tradicionales vinculadas a la emancipación tardía y el cuidado de personas mayores viudas $\mathrm{y} / \mathrm{o}$ divorciadas.

\section{Una interpretación de la distribución geográfica de los tipos de hogares en Europa a través del uso de la estadística espacial}

Para identificar la existencia de continuidades territoriales en las estructuras de hogares y evaluar la intensidad y grado de asociación espacial (autocorrelación vs independencia espacial) emplearemos dos indicadores de la estadística espacial. El primero de ellos, el indicador I Global Moran nos permitirá dilucidar si la distribución espacial de cada una de las formas familiares es al eatoria o presenta autocorrelación espacial entre las unidades territoriales estudiadas. El concepto de independencia espacial en el ámbito que estudiamos corresponde a unos tipos de hogares que se distribuyen en el territorio sin ninguna semejanza a como lo hacen sus regiones 
vecinas. Por el contrario, la autocorrelación espacial sugiere que las distribuciones de las estructuras de hogares en las unidades de análisis son similares a las de sus áreas vecinas. Los mapas que representan los indicadores local es de autocorrel ación espacial (LISA) nos permitirán matizar y/o corroborar al gunas de las conclusiones aportadas en el apartado descriptivo anterior, sometiendo ahora nuestras observaciones a un criterio de significación estadística.

El análisis descriptivo precedente ya detectaba la existencia de áreas geográficas con distribuciones similares de los tipos de hogares. El indicador Global Moran I para Europa muestra en todas las estructuras de hogares consideradas, la existencia de autocorrelación espacial, aunque las intensidades y extensiones superficiales afectadas sean muy desiguales. Es decir, las estructuras de hogares no se distribuyen en el espacio europeo de forma aleatoria y construyen clústeres de continuidad incluso transnacional (figura 3). El indicador Local Moran I presenta cuatro tipos de asociaciones espaciales posi bles entre las unidades NUTS3 y sus vecinas, y una quinta, no significativa que se asocia con la heterogeneidad espacial (ver tramas en la figura 3).

Cabe destacar como primer resultado que, a diferencia de otras distribuciones analizadas con estadística espacial, nuestros análisis apenas encuentran tipos de hogares con autocorrelación espacial negativa; es decir lugares con valores altos rodeados de valores bajos o viceversa. La tónica dominante en las estructuras de hogares es la autocorrelación espacial positiva sin que apenas se vislumbren en los mapas el aborados lugares singulares o atípicos respecto a sus entornos próximos.

En general, los hogares monoparentales, uniones consensual es y parejas casadas con hijos mayores de 25 años, vinculados estos últimos a la emancipación tardía de los jóvenes, son las estructuras de hogares que muestran un mayor grado de asociación espacial en el territorio europeo (tabla 6 y figura 3). Por el contrario, los hogares familiares y no familiares, estos últimos, en su modalidad unipersonal, muestran valores más bajos de asociación espacial que indican una menor extensión superficial de los espacios con autocorrelación espacial.

Los hogares familiares con un indicador Global Moran I de 0,426 y los hogares no familiares de 0,425 , revelan un claro contraste entre los países escandinavos, por una parte, y los mediterráneos y al gunas regiones de la Europa del Este, por otra. El mapa de ambos tipos de hogares por su complementariedad constituye una imagen invertida. En los países escandinavos y Estonia se localiza un área de autocorrelación espacial positiva con valores altos de hogares no familiares (trama roja). Por el contrario, España, Portugal, Croacia, Grecia, Polonia y Rumanía forman espacios de autocorrelación espacial de valores bajos en este tipo de hogares (tramas azules). Sorprende que la posición italiana, presumiblemente más cercana al conjunto de países mediterráneos, aparezca en ambos mapas de la figura 3 como un espacio de autocorrelación no significativa, con la excepción de las provincias del sur. Esta situación excepcional se explica por una distribución más heterogénea de los tipos de hogares familiares en Ital ia que la que se registra en la Península I bérica o Grecia, como ya se observaba claramente en la figura 2. 
Tabla 6. Indicador Global Moran's I de los tipos de hogares. Europa, circa 2011

\begin{tabular}{|c|l|c|}
\hline Siglas & Tipos de hogares & $\underline{\text { Ide Moran }}$ \\
\hline C1 & Hogares no familiares & $0,425^{* * *}$ \\
\hline C2 & Hogares unipersonales & $0,494^{* * *}$ \\
\hline C22 & Hogares unipersonales masculinos de 15 a 49 años & $0,513^{* * *}$ \\
\hline C23 & Hogares unipersonales masculinos de 50 a 64 años & $0,689^{* * *}$ \\
\hline C24 & Hogares unipersonales masculinos de más de 65 años & $0,693^{* * *}$ \\
\hline C25 & Hogares unipersonales femeninos de 15 a 49 años & $0,347^{* * *}$ \\
\hline C26 & Hogares unipersonales femeninos de 50 a 64 años & $0,658^{* * *}$ \\
\hline C27 & Hogares unipersonales femeninos de más de 65 años & $0,659^{* * *}$ \\
\hline C28 & Hogares unipersonales ambos sexos de 15 a 49 años & $0,441^{* * *}$ \\
\hline C29 & Hogares unipersonales de ambos sexos de más de 65 años & $0,662^{* * *}$ \\
\hline C3 & Hogares multipersonales & $0,620^{* * *}$ \\
\hline C4 & Hogares familiares & $0,426^{* * *}$ \\
\hline C5 & Hogares unifamiliares & $0,336^{* * *}$ \\
\hline C6 & Parejas casadas & $0,527^{* * *}$ \\
\hline C7 & Parejas casadas sin hijos & $0,667 * * *$ \\
\hline C8 & Parejas casadas con hijos menores de 25 años & $0,656^{* * *}$ \\
\hline C9 & Parejas casadas con hijos mayores de 25 años & $0,886^{* * *}$ \\
\hline C10 & Uniones consensuales & $0,890^{* * *}$ \\
\hline C11 & Uniones consensuales sin hijos residentes & $0,864^{* * *}$ \\
\hline C12 & Uniones consensuales con hijos menores de 25 años & $0,869^{* * *}$ \\
\hline C13 & Uniones consensuales con hijos mayores de 25 años & $0,753^{* * *}$ \\
\hline C20 & Hogares M onoparentales & $0,801^{* * *}$ \\
\hline C14 & Hogares monoparentales masculinos. & $0,875^{* * *}$ \\
\hline C15 & Hogares monoparentales masculinos con hijos menores de 25 años & $0,890^{* * *}$ \\
\hline C16 & Hogares monoparentales masculinos con hijos mayores de 25 años & $0,819^{* * *}$ \\
\hline C17 & Hogares monoparentales femeninos. & $0,824^{* * *}$ \\
\hline C18 & Hogares monoparentales femeninos con hijos menores de 25 años & $0,754^{* * *}$ \\
\hline C19 & Hogares monoparentales femeninos con hijos mayores de 25 años & $0,912^{* * *}$ \\
\hline C30 & Hogares monoparentales ambos sexos con hijos menores de 25 años & $0,725^{* * *}$ \\
\hline C21 & Hogares con 2 o más familias & $0,776^{* * *}$ \\
\hline
\end{tabular}

Fuente: Elaboración propia a partir de los datos obtenidos en Censushub2:

https://ec.europa.eu/CensusHub2/query.do? step =selectHyperCube\&qhc=false

Los hogares unipersonales de jóvenes y adultos, con un Global Moran I de 0,441 presentan autocorrelación espacial positiva $(+,+)$ en un espacio muy limitado del sur de Noruega y en sectores urbanos dispersos de Alemania, Dinamarca, los Países Bajos y la región de París. Este resultado es extremadamente interesante porque matiza la tesis de la STD que postula una extensión geográfica de mayor calado de esta forma innovadora de hogar. Las regiones con autocorrelación espacial positiva, de proporciones bajas en este tipo de hogares $(-,-)$, se extienden a lo largo de dos áreas discontinuas localizadas en el ámbito mediterráneo y, de forma más compacta, en los países del Este. En lo que se refiere a los hogares unipersonales de personas mayores (de >65 años), el Global Moran I es de 0,662, muy superior al de los jóvenes. Las áreas involucradas en la constitución de clústeres espaciales de este tipo de hogares son totalmente diferentes a las reseñadas para los hogares unipersonales de jóvenes y adultos. Los espacios de máxima expresión se encuentran en los Países Bálticos ${ }^{15}$, y de forma más discontinua a lo largo de espacios rural es en el norte y oeste de Reino Unido,

15 Las razones que propician el agrupamiento de esta forma familiar en los países del norte de Europa puede estar relacionada con los lazos familiares débiles que sugieren los trabajos de Reher 1998. 
centro de Francia y ciertos ámbitos dispersos del centro y norte de Italia, que podrían estar asociadas, de forma mayoritaria, con las estructuras de hogares típicas de los procesos de despoblación rural, pero también a la presencia de pensionistas del norte europeo en la costa francesa e italiana.

Los hogares integrados exclusivamente por parejas casadas, muestran un Global Moran I de 0,527 y una autocorrelación espacial de valores altos en España, Portugal, el sur de Italia, Grecia y amplios sectores de Croacia, Rumania, Polonia y el sur de Alemania. Se confirma la existencia de una amplia zona donde domina el modelo de formas familiares tradicionales que se extiende por buena parte de los países católicos dela Europa mediterránea y ortodoxos de la Europa Oriental. Por el contrario, las áreas con bajas proporciones de parejas casadas rodeadas por otras zonas de valores similares se localizan principalmente en un espacio continuo que ocupa la práctica totalidad de los países escandinavos y bálticos, donde existen tipos de hogares alternativos al matrimonio clásico como las uniones consensuales, o las derivadas de altas tasas de divorcio y/o rupturas de uniones consensuales que acaban generando numerosos hogares monoparentales, entre otras estructuras al ternativas de hogares.

El resto de áreas se distribuyen a lo largo del continente europeo de forma poco compacta sin clústeres espaciales destacables. Los hogares formados por parejas casadas sin hijos, con un indicador Global Moran I ya más elevado de 0,66, exhiben un clúster compacto de valores del tipo $(+,+)$ en Alemania y sectores del centro de Francia y Portugal y de valores bajos rodeados de valores bajos $(-,-)$, en un espacio continuo que se extiende desde los países bálticos hasta el centro-sur de Italia, en el que también se encuentran Polonia, la República Checa, Eslovaquia, Hungría, Austria, Eslovenia y Croacia, muchos de esos países con fecundidades entre las más bajas del mundo en torno a 2010. España no muestra valores significativos en esta variante familiar de las personas casadas, al igual que la mayor parte de las regiones NUTS 3 de los países nórdicos.

Las parejas casadas con hijos, tanto pequeños como mayores de 25 conforman un mapa de indicadores LISA que es la imagen invertida dela que presentan las parejas sin hijos. En el caso delas parejas con hijos pequeños, el Global Moran I es muy similar al de las parejas sin hijos. Lo más destacable en esta variante a escala regional es que España y Grecia presentan una distribución territorial mucho más homogénea que Italia, que se aleja del modelo general mediterráneo en su zona norte e insular en consonancia con las diferencias regionales de fecundidad registradas en ese país. Las parejas casadas con hijos mayores de 25 años constituyen el mapa de la emancipación tardía, con una autocorrelación espacial positiva del tipo $(+,+)$ frente a la emancipación temprana, autocorrelación espacial positiva de valores bajos (-,-). Este tipo de hogares presenta uno de los valores del indicador Global Moran I más elevado entre todas las formas analizadas, 0,886, convirtiéndose en una de las estructuras que mejor definen el paisaje regional de los hogares en Europa. 


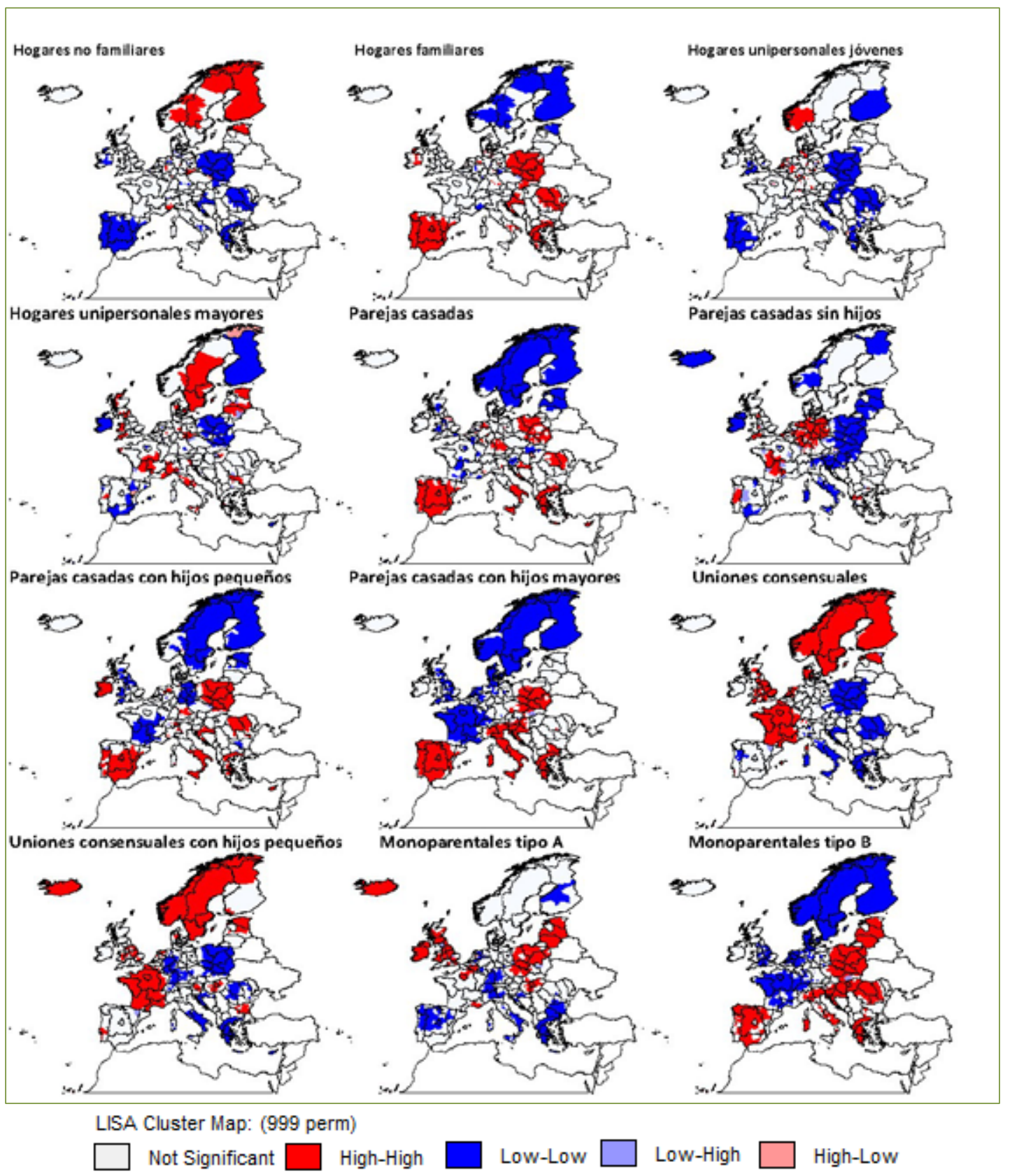

Figura 3. Indicadores locales de autocorrelación espacial (LISA) de los tipos de hogares en Europa a escala NUTS3, circa 2011

Fuente: Elaboración propia a partir de los datos de Eurostat (Censushub2)

https://ec.europa.eu/CensusHub2/query.do?step=selectHyperCube\&qhc=false

Las uniones consensuales, presentan un Global Moran I también muy significativo de 0,89 , entre los más elevados de todos los tipos de hogares analizados y constituyen el clúster territorial más compacto y homogéneo, extendiéndose por la totalidad de los países escandinavos, Dinamarca, Países Bajos, Estonia, Inglaterra y Gales. Esta tipología de uniones presenta dos características a destacar: es casi una imagen invertida del que ofrecen las parejas casadas con hijos mayores y muestra una estructura compacta nacional en los países de autocorrelación positiva del tipo $(+,+)$. De esta forma la edad de emancipación de los hijos, que distingue entre la permanencia en casa de los padres o la constitución de uniones consensuales, se convierte en uno de los factores 
estructurales que mayor incidencia tiene en la constitución de la geografía de los hogares en Europa.

Finalmente, los hogares monoparentales en todas sus variantes exhiben valores elevadísimos del indicador Global Moran, entre 0,754 y 0,912, y áreas también muy compactas de autocorrelación positiva de valores elevados. Entre las familias monoparentales encabezadas por mujeres con hijos pequeños se localiza un espacio geográfico continuo que incorpora a los países bálticos, Polonia, la República Checa y Hungría, amplios sectores de Reino Unido, la región de París y sectores del sur de Bél gica; el ámbito de autocorrelación espacial positiva de valores bajos (-,-) es mucho más disperso. Si nos concentramos en los hogares monoparentales de mujeres con hijos mayores, repetimos el esquema espacial de las parejas con hijos de estas edades aunque las zonas afectadas se caracterizan por una estructura espacial mucho más compacta. En resumen, parejas casadas con hijos mayores, uniones consensuales y familias monoparentales integran los tipos de hogares con mayor dependencia espacial, a lo que habría que añadir que las fronteras marcan discontinuidades o formas de transición de las estructuras de hogares señaladas por espacios con niveles no significativos de autocorrelación espacial.

\section{Los tipos de hogares que explican las diferencias regionales en Europa}

Este apartado tiene como objetivo identificar los tipos de hogares que contribuyen a explicar las diferencias geográficas entre NUTS 3. La técnica más apropiada para dar respuesta a esa pregunta es el análisis factorial o de componentes principales.

En la figura 4, se representa inicialmente un gráfico de componentes rotados que permite una identificación visual de la asociación entre 18 variables que recogen las proporciones de los tipos de hogares más comunes y los componentes o dimensiones (agrupaciones resúmenes de esas estructuras de hogares) ${ }^{16}$. Las asociaciones más significativas se resaltan mediante diferentes esferas. Los dos ejes del diagrama de dispersión miden el valor de la correlación de Pearson de cada variable con cada una de las dimensiones consideradas. La interpretación de estos factores se realiza en dos fases: en la primera se estudia conjuntamente el gráfico de componentes en el espacio rotado y la composición de las correlaciones de cada factor con las variables originales; en la segunda fase se atribuye un nombre a los factores de acuerdo con la estructura de las correlaciones de Pearson más significativas que podemos ver en la tabla 7.

16 Finlandia no proporciona datos para algunas formas familiares que hemos establecido como referentes por lo que no ha podido ser incluida en este tipo de análisis. 


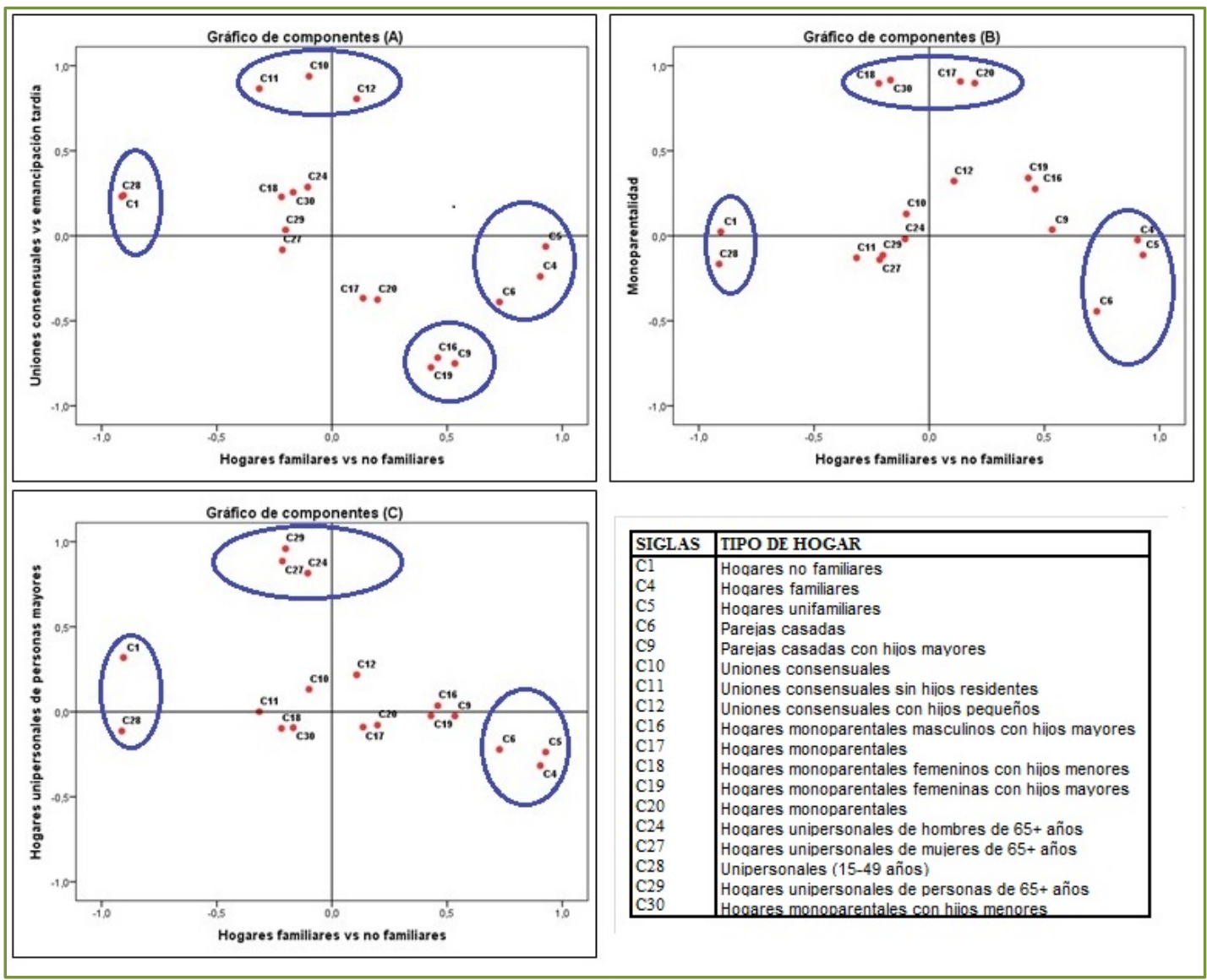

Figura 4 . Gráfico de componentes en el espacio rotado de los tipos de hogares en Europa

Fuente: Elaboración propia a partir de los datos de Eurostat (Censushub2)

https://ec.europa.eu/CensusHub2/query.do?step=selectHyperCube\&qhc=false

Hemos identificado cuatro factores que explican el $90,3 \%$ de la variabilidad de los tipos de hogares de las 1.340 unidades NUTS 3 analizadas (tabla 7). ¿En qué consisten estos factores?

El factor o dimensión número 1, que hemos denominado hogares familiares vs hogares no familiares explica el $27,18 \%$ de la varianza entre las regiones NUTS 3 y está correlacionado positivamente con los hogares familiares y negativamente con los hogares unipersonales de jóvenes y adultos y el conjunto las formas no familiares. Estos resultados resumen el contraste familiarismo vs individualismo y constituye el factor más explicativo. 
Tabla 7. Coeficientes de correlación de las puntuaciones factoriales con las variables que componen las dimensiones del análisis factorial de los tipos de hogares en Europa, circa 2011

\begin{tabular}{|c|c|c|c|c|}
\hline \multirow[b]{2}{*}{ Variables } & \multicolumn{4}{|c|}{ Dimensiones } \\
\hline & $\begin{array}{c}\text { Hogares } \\
\text { familiares vs no } \\
\text { familiares }\end{array}$ & $\begin{array}{c}\text { Uniones } \\
\text { consensuales vs } \\
\text { emancipación } \\
\text { tardía }\end{array}$ & Monoparentalidad & $\begin{array}{c}\text { Hogares } \\
\text { unipersonales } \\
\text { de personas } \\
\text { mayores }\end{array}$ \\
\hline Hogares no familiares &,- 905 & ,238 &, 024 & ,319 \\
\hline Unipersonales (15-49 años) &,- 912 & ,231 &,- 166 &,- 114 \\
\hline Hogares familiares & ,905 &,- 239 &,- 025 &,- 317 \\
\hline Hogares unifamiliares & ,928 &,- 063 &,- 113 &,- 237 \\
\hline Parejas casadas & ,727 &,- 390 &,- 445 &,- 222 \\
\hline Uniones consensuales &,- 099 & ,938 &, 129 & ,132 \\
\hline Uniones consensuales sin hijos residentes &,- 315 & ,865 &,- 130 &, 000 \\
\hline Uniones consensuales con hijos pequeños & ,108 & ,806 & ,321 &, 217 \\
\hline Parejas casadas con hijos mayores &, 534 &,- 751 & ,036 &,- 025 \\
\hline Hogares monoparentales masculinos con hijos mayores &, 460 &,- 717 & ,275 &, 035 \\
\hline Hogares monoparentales femeninos con hijos mayores &, 430 &,- 774 & ,340 &,- 023 \\
\hline Hogares monoparentales & ,135 &,- 367 & ,907 &,- 090 \\
\hline Hogares monoparentales femeninos con hijos menores &,- 219 & ,229 & ,896 &,- 098 \\
\hline Hogares monoparentales & , 198 &,- 376 & ,898 &,- 079 \\
\hline Hogares monoparentales con hijos menores &,- 168 & ,256 & ,916 &,- 094 \\
\hline Hogares unipersonales de hombres de 65+ años &,- 105 & ,286 &,- 019 & ,815 \\
\hline Hogares unipersonales de mujeres de $65+$ años &,- 215 &,- 083 &,- 141 & ,886 \\
\hline Hogares unipersonales de personas de $65+$ años &,- 201 &, 034 &,- 115 & ,959 \\
\hline Autovalores iniciales & 7,839 & 3,899 & 2,677 & 1,896 \\
\hline$\%$ Varianza explicada & 27,18 & 26,44 & 21,51 & 15,48 \\
\hline \% Varianza acumulada & 27,18 & 53,62 & 75,13 & 90,62 \\
\hline
\end{tabular}

Fuente: Elaboración propia a partir de los datos obtenidos en Censushub2:

https://ec.europa.eu/CensusHub2/query.do? step=selectHyperCube\&qhc=false

El segundo factor explica el $26,4 \%$ de la varianza. Dispone de una correlación altamente positiva con las uniones consensuales, y negativa con todos los tipos de hogares cuyos hijos permanecen hasta edades avanzadas en el hogar; se trata, por lo tanto, de la contraposición entre formas innovadoras de unión libre y la emancipación tardía de los jóvenes.

El tercer factor resumeel $21,5 \%$ de la varianza y presenta correlaciones positivas con todos los tipos de hogares vinculados a hogares monoparentales encabezados por mujeres divorciadas o madres solteras que tienen hijos menores.

El último factor explica el 15,5\% de la varianza. Está asociado con los hogares unipersonales de personas mayores.

En resumen, se confirman como factores con mayor poder explicativo de las diferencias espaciales de los tipos de hogares en Europa algunas de las estructuras de hogares asociadas con la Segunda Transición Demográfica y reseñadas por la literatura científica en el apartado 2 de este trabajo: el contraste entre los hogares no familiares (unipersonales de jóvenes adultos) y el familiarismo del sur, las uniones consensuales en los países más avanzados frente a la emancipación tardía de los países mediterráneos, la monoparentalidad en el Este de Europa y los efectos combinados de la despoblación en los hogares rurales europeos y los asociados con formas más individualistas de retiro en el norte de Europa, que se manifiesta en los hogares unipersonales encabezados por personas mayores de 65 años.

En la figura 5, se presenta la distribución estadística por quintiles de las puntuaciones factoriales de las 4 dimensiones construidas. Las categorías muy altas, 
las que pertenecen al Q5 representan correlaciones muy elevadas con el factor en cuestión y las muy bajas tienen una correlación negativa con el factor en cuestión (Q1). Por ejemplo, en el factor hogares familiares vs hogares no familiares las puntuaciones al tas que se localizan en el sur de Europa están vinculadas con el familiarismo mientras las que se encuentran en los quintiles más bajos (Q1 y Q2), dispersas por el norte de Europa, están asociadas con las formas no familiares.

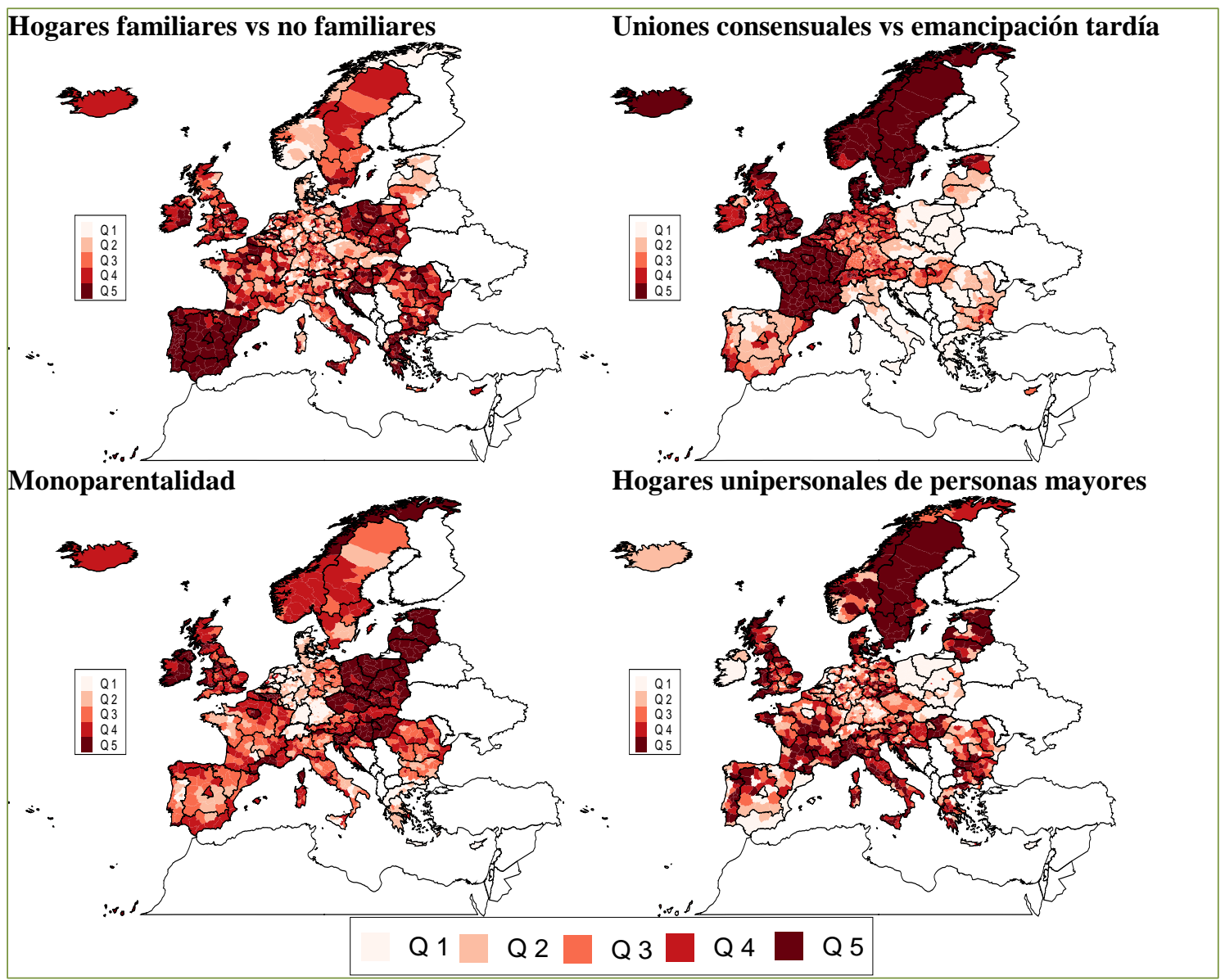

Figura 5. Distribución geográfica por quintiles de las puntuaciones factoriales a escala NUTS3, circa 2011

Fuente: Elaboración propia a partir de los datos de Eurostat (Censushub2)

https://ec.europa.eu/CensusHub2/query.do? step=selectHyperCube\&qhc=false

Las puntuaciones más elevadas del primer factor están asociadas con las formas familiares más tradicionales (familias nucleares) dominantes en las regiones del sur de Europa: la práctica total idad de España y Portugal, las regiones del sur deltalia, Croacia y Grecia, así como amplios sectores de Polonia e Irlanda y una distribución más dispersa y heterogénea en el resto de Europa.

El segundo factor asociado positivamente con las uniones consensuales y negativamente con la emancipación tardía muestra los valores más elevados en los países nórdicos, Dinamarca, Países Bajos, Francia y Reino Unido, es de menor entidad en Alemania y adquiere valores muy bajos en los países del sur de Europa donde la emancipación es tardía y las uniones consensuales apenas despuntan. 
La dimensión asociada a la monoparentalidad adquiere las máximas puntuaciones en el Este de Europa, como ya ha sido profusamente referido a lo largo del trabajo.

Las puntuaciones factoriales vinculadas a la dimensión de los hogares unipersonales de personas mayores presentan una distribución geográfica más heterogénea, con un núcleo espacial de mayor densidad en los países nórdicos y países bálticos, sectores rurales de Francia, Reino Unido, Italia y la franja fronteriza entre Portugal y España, y un escaso impacto en las regiones mediterráneas de España, numerosas áreas de Alemania y el conjunto de Polonia.

\section{Una tipología geográfica de síntesis de los tipos de hogares en Europa}

Finalmente, presentamos una distribución espacial de síntesis de los 18 tipos de hogares que permiten resumir el conjunto de estructuras de hogares que definen cada región NUTS 3 en Europa. Esta distribución ha sido elaborada tras aplicar el análisis de conglomerados a las puntuaciones de los cuatro factores identificados en el apartado anterior. Los clústeres que vamos a enumerar a continuación se definen por ciertos caracteres especiales que les dotan de una singularidad respecto a los otros grupos que hemos identificado.

A continuación, pasamos a describir las características principales y la distribución geográfica de los cinco conglomerados o clústeres (Tabla 8 y Figura 6).

El clúster número 1, está vinculado con las áreas geográficas donde abundan las parejas casadas, la emancipación tardía, que se deduce por la elevada proporción de las parejas en las que permanecen hijos de más de 25 años, y los hogares unipersonales de mujeres mayores de 65 años. Esta tipología corresponde a los hogares tradicionales del sur de Europa, donde se registra un bajo nivel de uniones consensuales y monoparental es con hijos pequeños. Se trata, por una parte, de regiones poco pobladas y/o envejecidas localizadas en el sur del continente europeo. Su área de distribución geográfica se encuentra en las áreas rurales dela España interior y Portugal, el conjunto de las regiones italianas con la excepción de Roma, la mayor parte de Croacia, Grecia y sectores dispersos de Bulgaria, Rumanía y Alemania. Este agrupamiento representa el 23,6 por ciento de las regiones NUTS 3 de Europa.

El segundo agrupamiento de regiones, se caracteriza por la dominancia de los hogares familiares, parejas casadas con hijos menores y por la escasa penetración de los hogares unipersonales, con la excepción de los encabezados por mujeres mayores de 65 años. Setrata de un espacio de fuerte nuclearización que se extiende por las áreas más pobladas de España, regiones centrales de Francia, el conjunto de Irlanda, la mayor parte de Rumania, sectores dispersos de Grecia, Bulgaria y Polonia. En las regiones centrales de Europa destaca un continuo espacial de este conglomerado que aglutina grandes extensiones de los Países Bajos, el norte de Bélgica, Alemania, Suiza, Austria y Eslovaquia. En el otro extremo, esta agrupación tiene escaso eco en Reino Unido y Noruega y está especialmente ausente en los países nórdicos, bálticos y 
numerosas regiones de los paíes del Este. El clúster contiene el 40,7 por ciento de las regiones NUTS 3 y es el más extenso de Europa.

Tabla 8. Media de las proporciones de los diferentes tipos de hogar por tipo de conglomerado

\begin{tabular}{|c|c|c|c|c|c|c|}
\hline \multirow{2}{*}{ Tipos de hogares } & \multirow[b]{2}{*}{1} & \multirow[b]{2}{*}{2} & \multicolumn{2}{|l|}{ Clúster } & \multirow[b]{2}{*}{5} & \multirow[b]{2}{*}{ Total } \\
\hline & & & 3 & 4 & & \\
\hline Hogares no familiares & $3.316,7$ & $3.144,5$ & $4.755,7$ & $3.614,4$ & $3.309,6$ & $3.405,6$ \\
\hline Hogares unipersonales & $3.086,2$ & $2.925,8$ & $4.442,7$ & $3.274,9$ & $2.936,7$ & $3.138,4$ \\
\hline Hogares unipersonales masculinos de 15 a 49 años & 623,4 & 715,8 & $1.291,5$ & 669,5 & 626,9 & 724,6 \\
\hline Hogares unipersonales masculinos de 50 a 64 años & 315,0 & 308,2 & 405,5 & 388,6 & 354,5 & 334,9 \\
\hline Hogares unipersonales masculinos de más de 65 años & 342,1 & 279,6 & 314,2 & 408,4 & 274,3 & 312,4 \\
\hline Hogares unipersonales femeninos de 15 a 49 años & 366,7 & 440,7 & 938,6 & 389,0 & 372,7 & 449,5 \\
\hline Hogares unipersonales femeninos de 50 a 64 años & 318,3 & 327,4 & 460,2 & 405,5 & 407,4 & 358,1 \\
\hline Hogares unipersonales femeninos de más de 65 años & $1.063,6$ & 840,2 & $1.023,4$ & $1.011,0$ & 882,2 & 935,8 \\
\hline Hogares unipersonales ambos sexos de 15 a 49 años & 990,0 & $1.156,5$ & $2.230,0$ & $1.058,5$ & 999,6 & $1.174,1$ \\
\hline Hogares unipersonales de ambos sexos de más de 65 años & $1.405,7$ & $1.119,8$ & $1.337,6$ & $1.419,4$ & $1.156,5$ & $1.248,2$ \\
\hline Hogares multipersonales & 230,0 & 218,2 & 312,5 & 338,9 & 372,5 & 266,7 \\
\hline Hogares familiares & $6.682,8$ & $6.853,5$ & $5.243,8$ & $6.385,1$ & $6.686,5$ & $6.592,8$ \\
\hline Hogares unifamiliares & $6.450,4$ & $6.639,3$ & $5.154,3$ & $6.294,5$ & $6.284,5$ & $6.372,4$ \\
\hline Parejas casadas & $5.033,2$ & $4.980,8$ & $3.645,6$ & $4.195,6$ & $4.320,0$ & $4.684,2$ \\
\hline Parejas casadas sin hijos & $2.239,4$ & $2.229,6$ & $2.050,5$ & $2.273,5$ & $1.623,9$ & $2.132,5$ \\
\hline Parejas casadas con hijos menores de 25 años & $2.181,2$ & $2.349,2$ & $1.412,3$ & $1.697,9$ & $2.197,1$ & $2.126,5$ \\
\hline Parejas casadas con hijos mayores de 25 años & 611,6 & 400,9 & 181,8 & 223,1 & 498,1 & 424,3 \\
\hline Uniones consensuales & 516,1 & 801,4 & 754,4 & $1.214,8$ & 613,5 & 753,2 \\
\hline Uniones consensuales sin hijos residentes & 275,5 & 453,3 & 520,3 & 582,7 & 275,1 & 406,7 \\
\hline Uniones consensuales con hijos menores de 25 años & 226,6 & 335,8 & 228,1 & 617,8 & 321,6 & 333,4 \\
\hline Uniones consensuales con hijos mayores de 25 años & 13,0 & 10,9 & 5,0 & 13,2 & 15,8 & 11,9 \\
\hline Hogares Monoparentales & 894,8 & 830,0 & 743,3 & 875,4 & $1.331,8$ & 917,6 \\
\hline Hogares monoparentales masculinos. & 159,2 & 147,3 & 98,5 & 150,5 & 186,8 & 152,1 \\
\hline Hogares monoparentales masculinos con hijos menores de 25 años & 85,7 & 97,8 & 71,6 & 114,8 & 112,7 & 97,0 \\
\hline Hogares monoparentales masculinos con hijos mayores de 25 años & 72,9 & 48,7 & 26,5 & 35,2 & 73,7 & 54,5 \\
\hline Hogares monoparentales femeninos. & 735,6 & 682,8 & 644,8 & 724,9 & $1.145,0$ & 765,5 \\
\hline Hogares monoparentales femeninos con hijos menores de 25 años & 401,9 & 465,9 & 519,4 & 582,5 & 750,8 & 511,8 \\
\hline Hogares monoparentales femeninos con hijos mayores de 25 años & 333,2 & 216,2 & 124,9 & 142,0 & 393,8 & 253,1 \\
\hline Hogares monoparentales ambos sexos con hijos menores de 25 años & 487,6 & 563,7 & 591,0 & 697,2 & 863,5 & 608,8 \\
\hline Hogares con 2 o más familias & 231,4 & 213,2 & 88,5 & 89,6 & 401,0 & 219,3 \\
\hline Número de casos & 316 & 546 & 115 & 165 & 198 & 1340 \\
\hline
\end{tabular}

Nota: Finlandia no dispone de toda la información necesaria (faltan sus 19 regiones).

Fuente: Elaboración propia a partir de los datos de Eurostat (Censushub2)

https://ec.europa.eu/CensusHub2/query.do?step=selectHyperCube\&qhc=false

El conglomerado número 3, que está compuesto por regiones NUTS 3 con una destacada presencia de hogares unipersonales de jóvenes y adultos y menor protagonismo de los hogares familiares, corresponde a numerosas áreas urbanas del centro y norte de Europa ${ }^{17}$, especial mente destacable en los centros universitarios más importantes de Europa. El número de regiones en este conglomerado es el más reducido representado solo el 8,6 por ciento de las regiones NUTS 3 europeas.

El clúster número 4, se caracteriza por una presencia significativa de las parejas sin hijos y las uniones consensuales; se trata, por tanto, de la tipología en la que se encuentran los tipos de hogares más modernos, identificados con algunos de los parámetros que caracterizan la Segunda Transición Demográfica y descritos en el apartado 2 del artículo. Supone el 12,3 por ciento de las regiones analizadas. Se extiende por Francia, la región valona de Bélgica, Reino Unido, la práctica totalidad de Suecia y extensas regiones de Noruega. A parece de forma más dispersa en áreas del sur de Austria.

17 Ogden y Hall 2000 y 2004 encuentran en los centros urbanos de Francia unos de los focos de expansión de los hogares unipersonales. 
El conglomerado número 5, está dominado por las formas monoparentales encabezadas por mujeres. Constituye un área muy compacta en el este de Europa, la totalidad de los países bálticos, la mayoría de la República Checa, Polonia, Hungría y Eslovaquia. En estas zonas la forma de monoparentalidad está capitaneada por mujeres jóvenes. También pertecen a este clúster otras zonas particulares como Irlanda del Norte, las regiones urbanas de Escocia, la región de Londres y sectores dispersos en la isla de Cerdeña, el centro y norte de Italia, estos últimos asociados con la monoparentalidad de mujeres de más de 65 años.

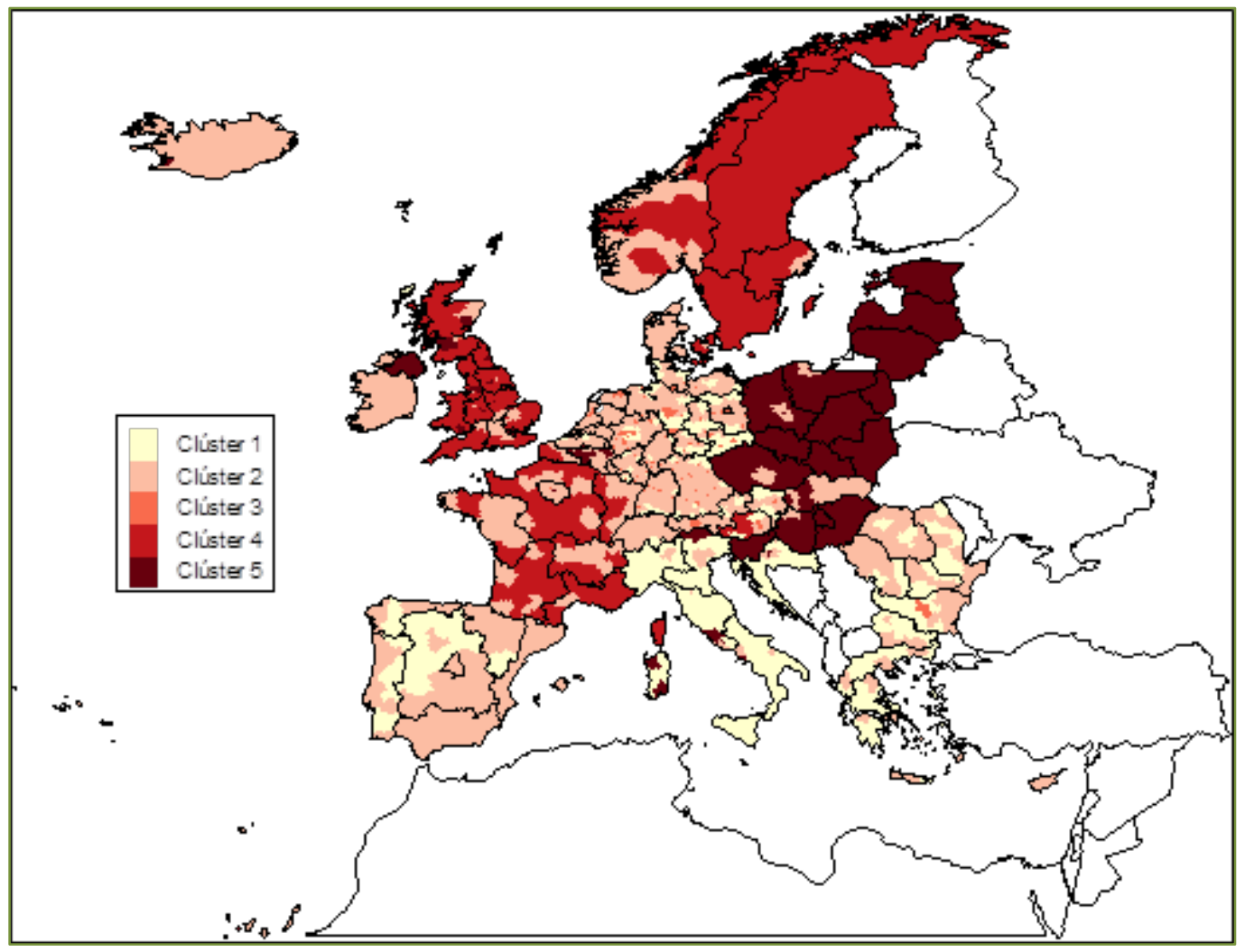

Figura 6. Distribución geográfica de los clústeres de tipos de hogares en Europa a escala NUTS3, circa 2011

Fuente: Elaboración propia a partir de los datos de Eurostat (Censushub2)

https://ec.europa.eu/CensusHub2/query.do?step=selectHyperCube\&qhc=false

El análisis de conglomerados que hemos efectuado nos ha permitido construir un mapa sintético de los tipos de hogares en Europa (Figura 6) que rebate a escala regional, y con otras cartografías previas en el artículo (Figuras 2, 3 y 5) la pretendida convergencia de las tipologías de hogares producto de la teoría de la Segunda Transición Demográfica. El mapa se inclina más bien por un aumento de la heterogeneidad espacial y, por tanto, por la existencia de una mayor complejidad estructural en Europa, donde conviven formas tradicionales mientras se consolidan en ciertos espacios geográficos otras más innovadoras asociadas a la teoría de la Segunda Transición Demográfica. 


\section{Conclusiones}

Pasamos a enumerar a continuación las principales conclusiones de este estudio, a las que hemos llegado a partir de una triple dimensión: epistemológica, heurística y metodológica. Queremos reivindicar, en primer lugar, el interés y la necesidad de que la geografía asuma un mayor protagonismo en los estudios sobre los hogares; en segundo lugar, reconocer las potencialidades de la fuente empleada, que nos ha permitido realizar una comparación simultánea de las estructuras de hogares en 32 países y 1.340 regiones europeas; y, en último lugar, ratificar, positivamente, las múltiples técnicas de análisis estadístico y espacial empleadas.

Respecto a los resultados globales, no debemos olvidar que, a pesar de la complejidad espacial de las estructuras de hogares, la forma predominante de convivencia en toda Europa sigue siendo la de una población que vive en núcleos familiares representados por hogares conyugales, con o sin hijos, y sus formas derivadas $\mathrm{y} / \mathrm{o}$ colaterales como las uniones consensuales $y$ las familias monoparentales.

Los datos de la ronda censal de 2010 confirman, en lo esencial, los resultados obtenidos en estudios nacionales previos, enriquecidos ahora por el acceso a la información censal de buena parte de los países del Este: un sur donde aún dominan los tipos de hogares con un tamaño medio superior al conjunto europeo, los países del norte y centro de Europa con una distribución más heterogénea de los tipos de hogares y de tamaño más pequeño, y un conjunto de países del Este que se encuentran a medio camino entre uno y otro modelo. Aunque los avances en la Segunda Transición Demográfica (STD) han vuelto más complejos los ciclos de vida familiar en Europa, los resultados que presentamos a escala nacional sugieren que se mantienen, e incluso aumentan, las diferencias territoriales existentes con anterioridad a dicha transición en lugar de la convergencia temporal de las estructuras, aunque este es un tema a investigar más profundamente.

Aún más, al incorporar la escala regional de análisis a través de los datos de las áreas NUTS 3 se constata, con más intensidad, la existencia de una gran diversidad espacial de tipos de hogares en Europa, a la vez que se ofrecen más argumentos para contradecir las tesis sobre la convergencia de las estructuras de hogares que auspicia la teoría de la STD. El mapa se inclina más bien por un aumento de la heterogeneidad espacial y, por tanto, una complejidad de los tipos de hogares en la que conviven las formas tradicionales y las más innovadoras dentro el mismo ámbito europeo.

La introducción de la escala regional en el análisis de las estructuras de hogares supone un avance notable en la caracterización de las relaciones entre espacio y hogares. Este tipo de escala nos ha permitido constatar dos efectos importantes que ocultan los análisis basados en los agregados nacionales: a) la existencia de diversidad regional interna en la distribución de los distintos tipos de hogar, tanto los tradicionales como las formas emergentes $y, b$ ) la constatación de un variado mosaico regional de tipos de hogares a escala europea que trasciende las fronteras nacionales. La variabilidad geográfica de los hogares familiares y las parejas casadas es pequeña. Apenas existen diferencias entre países. Sin embargo, otras formas más modernas en 
consonancia con la teoría de la STD, como los hogares unipersonales de jóvenes, las uniones consensuales y las familias monoparentales de diverso tipo -complementadas con otras variantes más arraigadas en ciertos sectores geográficos europeos, como las parejas casadas con hijos mayores-, muestran una elevada diversidad tanto interna como entre países. Existen, por lo tanto, especificidades nacionales que se conservan lejos de una pretendida convergencia europea.

Los nuevos tipos de hogares que se desarrollan con la Segunda Transición Demográfica tienen, sin embargo, un papel destacado como factores explicativos de las actuales diferencias geográficas regi onales en las estructuras de hogares. Por otra parte, no podemos ignorar que la permanencia de ciertos tipos de hogares más tradicionales es el otro ámbito sobre el que se sustenta esta diversidad geográfica, y que tiene como características básicas: a) la diferencia en la importancia de los hogares no familiares (unipersonales de jóvenes adultos), b) el familiarismo del sur, c) las uniones consensuales en los países más avanzados, d) la emancipación tardía, e) la monoparentalidad en el Este de Europa, y f) los efectos combinados de la despoblación en los hogares rurales europeos y los asociados con formas más individualistas de retiro en el norte de Europa.

Las técnicas de estadística espacial aplicadas en este artículo nos permiten reclamar el papel determinante del espacio en el análisis de los tipos de hogares. Los datos recabados en nuestro trabajo confirman que no existe independencia espacial en la distribución geográfica de las estructuras de hogares en Europa. Todos los tipos de hogares presentan una autocorrelación espacial positiva y significativa, pero con intensidades y superficies afectadas de grado muy desigual. Son escasos los espacios singulares con autocorrelación espacial negativa y, en general, todos ellos están vinculados a la localización de hogares unipersonales de jóvenes y adultos, u otras formas innovadoras que se encuentran en contextos urbanos.

Las fronteras constituyen el límite geográfico donde la acción de los diferentes marcos legales, institucionales y de los sistemas de bienestar nacional se manifiestan y favorecen la emergencia de nuevas estructuras de hogares o el mantenimiento de ciertas formas familiares tradicionales. Como ejemplo, téngase en cuenta, por una parte, la acción proactiva del Estado francés amparando con sus ayudas sociales una emancipación temprana de los jóvenes o, en el caso italiano y español, retrasando, por la inexistencia de políticas públicas, la emancipación del mismo grupo de población. Las fronteras nacionales siguen siendo importantes zonas de transición, muchas veces vinculadas a clústeres que la estadística espacial asigna como espacios sin significación estadística en ninguna de las formas de autocorrelación espacial consideradas.

Los datos empíricos respaldan, por tanto, la imagen de unas estructuras de hogares en Europa que constituyen un mosaico geográfico lejos de la imagen de convergencia estructural que auspiciaba la teoría de la Segunda Transición Demográfica. Donde tanto los hogares unipersonales de jóvenes, las uniones consensual es y las familias monoparentales conviven con adaptaciones de estructuras conyugales clásicas a las dificultades económicas coyunturales y estructurales, que reflejan las parejas casadas con hijos mayores de 25 años, vinculadas a la emancipación 
tardía. Ambos factores contribuyen con igual peso a definir el mosaico geográfico de los tipos de hogares en Europa. La tipología que hemos establecido muestra una distribución geográfica de hogares que aúna a la vez heterogeneidades intranacionales, efectos de las barreras nacionales, identifica islas urbanas separadas de sus entornos más rurales, así como la extensión de ciertas estructuras que trascienden las fronteras nacionales. En suma, el artículo refleja una Europa caracterizada por la heterogeneidad geográfica de los tipos de hogares que parece rebatir, o más bien matizar, la tesis de convergencia de las formas familiares atribuida a la teoría de la Segunda Transición Demográfica y, constata el mantenimiento de ciertas especificidades territoriales, especialmente en lo que se refiere a la permanencia de los tipos de hogares tradicionales en amplios sectores geográficos del sur de Europa.

En resumen, los resultados obtenidos confirman, por una parte, la importancia de los nuevos tipos de hogares como factores explicativos de las actuales diferencias geográficas en las estructuras familiares y, por otra parte, rebaten la tesis que las transformaciones sociodemográficas vinculadas a la Segunda Transición Demográfica estén provocando una convergencia de los tipos de hogares en Europa. La causa es que el peso histórico de ciertas formas familiares, las prácticas y costumbres tradicionales y los fuertes y sólidos lazos de amistad y parentesco están muy arraigados en determinadas áreas de Europa y siguen condicionando la permanencia de las estructuras de hogares más tradicionales que no mutan de forma, pero sí de función y contenido.

\section{Bibliografía}

Anselin, L. 1995. "Local indicators of spatial association-LISA." Geographical Analysis 27 (2): 93-115.

Billari, Francesco C.; Liefbroer, Aart C. 2010. "Towards a new pattern of transition to adulthood?." Advances in Life Course Research 15 (2-3): 59-75.

Bizquerra, R. 1999. Introducción conceptual al análisis multivariable. Barcelona: PPU.

Bonvalet, Catherine; Gotman, Anne. 1999. La famille et ses proches: L'aménagement des territoires. Paris: INED.

Buchmann, Marlis C.; Kriesi, Irene. 2011. "Transition to adulthood in Europe." Annual review of sociology 37: 481-503.

Chacón Jiménez, Francisco. 1991. "Nuevas tendencias de la demografía histórica en España: las investigaciones sobre historia de la familia." Revista de Demografía Histórica, 9 (2) : 79-98.

Chesnais, J ean-Claude. 1986. "La transition démographique: étapes, formes, implications économiques. Etude de séries temporelles (1720-1984) relatives à 67 pays." Population: 1059-1070.

Domingo, Andreu y Bayona, J ordi. 2010. "Los hogares de la población de nacionalidad extranjera en España en el año 2001." Papers: revista de sociologia 95 (3): 731- 754. 
Das gupta, Monica. 1999. "Lifeboat versus corporate ethic: Social and demographic implications of stem and joint families." Social Science \& M edicine 49 (2): 173-184. Duranton, Gilles; Rodríguez-pose, Andrés y Sandall, Richard. 2009. "Family types and the persistence of regional disparities in Europe." Economic geography 85 (1): 2347.

Durkheim, Émile. 1921. “La famille conjugale”. Revue philosophique 90 (1): 13.

Esping-Andersen, Gosta. 1990. The three worlds of welfare capitalism. Princeton: Princeton University Press.

Ferrera, Maurizio. 1996. "The Southern model of welfare in social Europe." J ournal of European social policy 6 (1): 17-37.

Flaquer, Lluís. 2000. Las políticas familiares en una perspectiva comparada. Barcelona: Fundación "La Caixa".

Fodor, Eva, et al. 1997. "Family policies and gender in Hungary, Poland, and Romania." Communist and post-communist studies 35 (4): 475-490.

Fokkema, Tineke; Liefbroer, Aart C. 2008. "Trends in living arrangements in Europe: Convergence or divergence?". Demographic research 19: 1351-1418.

Gauthier, Anne H. 2007. "The impact of family policies on fertility in industrialized countries: a review of the literature." Population research and policy review 26 (3): 323-346.

Gottschall, Karin; Bird, Katherine. 2003. "Family Leave Policies and Labor Market Segregation in Germany: Reinvention or Reform of the Male Breadwinner Model?". Review of Policy Research 20 (1): 115-134.

Gullestad, Marianne y Segalen, Martine. (dir.). 1995. La famille en Europe. Parenté et perpétuation familiale, Paris : La Découverte.

Gullestad, Marianne; Segalen, Martine (ed.). 1997. Family and kinship in Europe. Paris: A\&C Black.

Hajnal, John. 1965. "European marriage patterns in perspective". En: Population in history: essays in historical demography, editado por John Hajnal, David Glass, David EC. Eversley, 101-43. Chicago, Illinois: Aldine Publishing Company-

Hajnal, John. 1982. "Two kinds of preindustrial household formation system." Population and development review: 449-494.

Hank, Karsten. 2007. "Proximity and contacts between ol der parents and their children: A European comparison". J ournal of Marriage and Family 69 (1): 157-173.

Heady, P., Gruber, S., y Ou, Z. 2010. "Family, kindred and marriage." En Family, kinship and state in contemporary, editado por P. Heady y M. Kohli, 31-70. Frankfurt Campus: Perspectives on theory and policy.

Heuveline, Patrick; Timberlake, J effrey M. 2004. "The role of cohabitation in family formation: The United States in comparative perspective."J ournal of marriage and family 66 (5):1214-1230.

Heuveline, Patrick; Timberlake, J effrey M.; Furstenberg, Frank F. 2003. "Shifting childrearing to single mothers: Results from 17 western countries." Population and Development Review 29 (1): 47-71. 
Höllinger, Franz; Haller, Max. 1990. "Kinship and social networks in modern societies: A cross-cultural comparison among seven nations." European Sociological Review 6 (2): 103-124.

Inglehart, Ronald F. 2008. "Changing values among western publics from 1970 to 2006." West european politics 31 (1-2): 130-146.

J urado Guerrero, Teresa; Naldini, Manuela. 1996. "Is the South so different? Italian and Spanish families in comparative perspective." South European Society and Politics 1 (3): 42-66.

Kalmijn, Matthijs. 2007. "Explaining cross-national differences in marriage, cohabitation, and divorce in Europe, 1990-2000." Population studies 61 (3): 243263.

Keilman, Nico. 2003. Demographic implications of low fertility for family structures in Europe. Council of Europe.

Keilman, Nico. 1988. "Recent trends in family and household composition in Europe." European J ournal of Population/Revue européenne de Démographie, 3 (3-4): 297325.

Kiernan, Kathleen. 2001. “The rise of cohabitation and childbearing outside marriage in Western Europe." International journal of law, policy and the family 15 (1): 1-21.

Kreyenfeld, Michaela. 2004. "Fertility decisions in the FRG and GDR: An analysis with data from the German Fertility and Family Survey." Demographic Research 3: 275318.

Kuijsten, Anton C. 1996. "Changing family patterns in Europe: A case of divergence?." European J ournal of Population/Revue Européenne de Démographie 12 (2): 115-143. Laslett, P. 1983. "Family and household as work group and kin group: Areas of traditional Europe compared". En Family forms in historic Europe, editado por R. Wall, P. Laslett y J. Robin, 513-564. Cambridge: University Press.

Laslett, Peter; wall, Richard. 1972. "Household and Family in Past Time: Comparative Studies in the Size and Structure of the Domestic Group over the Last Three Centuries in England, France, Serbia, Japan, and Colonial North America." Cambridge: University Press.

Lesthaeghe, Ron. 2010. "The unfolding story of the second demographic transition." Population and devel opment review 36 (2): 211-251.

Lesthaeghe, Ron; Van de Kaa, Dirk J. 1986. “Two demographic transitions.” Population growth and decline: 9-24.

Leung, Yee; Mei, Chang-Lin; Xhang, Wen-Xiu. 2003. "Statistical test for local patterns of spatial association". Environment and Planning A 35 (4): 725-744.

Livi Bacci, M. 1990. Historia Mínima de la Población Mundial. Barcelona: Ariel.

Lohmann, Henning; Zagel, Hannah. 2016. "Family policy in comparative perspective: The concepts and measurement of familization and defamilization."J ournal of European Social Policy 26 (1): 48-65. 
López-gay, Antonio; Esteve, Albert; López-Colás, J ulián; Permanyer, Iñaki; Turu, Anna; Lesthaege, Ron. 2015. “Geografía de la unión libre en América Latina y El Caribe a comienzos del siglo XXI."Scripta Nova. Revista Electrónica de Geografía y Ciencias Sociales XIX (509).

Micheli, Giuseppe A. 2012. “Two strong families in Southern Europe? Re-examining the geography of kinship regimes stemming from the reciprocity mechanisms between generations." European Journal of Population/Revue européenne de Démographie 28 (1): 17-38.

Mikelarena, Fernando. 1992. "Las estructuras familiares en la España tradicional: geografía y análisis a partir del censo de 1860." Revista de Demografía Histórica 10 (3): 15-62.

Monkediek, Bastian; bras, Hilde AJ. 2016. "The interplay of family systems, social networks and fertility in Europe cohorts born between 1920 and 1960." Economic History of Developing Regions 31 (1): 136-166.

Moreno, Rosina y Vayá, Esther. 2000. Técnicas econométricas para el tratamiento de datos espaciales: la econometría espacial. Barcelona: Edicions Universitat Barcelona.

Mulder, Clara H.; Cooke, Thomas J. 2009. "Family ties and residential locations." Population, space and place 15 (4): 299-304.

Mason, Karen Oppenheim. 2001. "Gender and family systems in the fertility transition." Population and Development Review 27: 160-176.

Ogden, Philip E.; hall, Ray. 2004. "The second demographic transition, new household forms and the urban population of France during the 1990s." Transactions of the Institute of British Geographers 29 (1): 88-105.

Ogden, Philip E.; Hall, Ray. "Households, reurbanisation and the rise of living al one in the principal French cities, 1975-90." Urban Studies 37(2): 367-390.

Parsons, Talcott. 1943. "The kinship system of the contemporary United States." American anthropologist 45 (1): 22-38.

Pfirsch, Thomas. 2011. "Une géographie de la famille en Europe du Sud." Cybergeo: European J ournal of Geography. Espace, Société, Territoire 533.

Potârcă, Gina; Mills, Melinda; Lesnard, Laurent. 2013. "Family formation trajectories in Romania, the Russian Federation and France: Towards the second demographic transition?" European J ournal of Population/Revue européenne de Démographie 29 (1): 69-101.

Reher, David Sven. 1998. "Family ties in Western Europe: persistent contrasts." Population and Development Review 24 (2): 203-234.

Reher, David Sven. 1996. La familia en España, pasado y presente. Madrid: Alianza Editorial.

Roussel, Louis. 1986. "L'évolution récente de la structure des ménages dans quelques pays industriels." Population 41 (6): 913-934.

Roussel, Louis. 1992. "La famille en Europe Occidentale: divergences et convergences." Population 47 (1): 133-152.

Rowland, Donald T. 2007. "Historical trends in childlessness." J ournal of family Issues 28 (10): 1311-1337. 
Ruggles, Steven. 2009. "Reconsidering the Northwest European family system: Living arrangements of the aged in comparative historical perspective." Population and Development Review 35 (2): 249-273.

Skinner, G. William. 1997. "Family systems and demographic processes." En Anthropological demography. Toward a new synthesis, editado por D. I. Kertzer \& T. E. Fricke, 53-95. Chicago: The University of Chicago Press.

Sobotka, Tomáš; Toulemon, Laurent. 2008. "Overview Chapter 4: Changing family and partnership behaviour: Common trends and persistent diversity across Europe." Demographic research 19 (6): 85-138.

Solsona, M. y Treviño, R. 1990. Estructuras familiares en España. Madrid: Instituto de la Mujer.

Therborn, Göran. 2004. Between sex and power: Family in the world 1900-2000. Routledge. Thomson, Elizabeth. 2014. "Family Complexity in Europe." The Annals of the American Academy of Political and Social Science 654 (1): 245-258.

Todd, Emmanuel. 1990. L'invention de l'Europe. Paris: Seuil.

Todd, Emmanuel. 1999. La diversité du monde: structures familiales et modernité. Paris: Seuil.

Van de Kaa, Dirk J. 1987. “Europe's second demographic transition."Population Bulletin, 42 (1): 1-59.

Van Winkle, Zachary. 2018. "Family Trajectories Across Time and Space: Increasing Complexity in Family Life Courses in Europe?" Demography 55 (1): 135-164.

Viazzo, Pier Paolo. 2003. "What's so special about the Mediterranean? Thirty years of research on household and family in Italy."Continuity and change 18 (1): 111-137.

Wall, Richard. 1992. "Comparer ménages et familles au niveau européen: Problèmes et perspectives." Population 51 (1): 93-115.

Wellings, Kaye; Kane, Roslyn. 1999. "Trends in teenage pregnancy in England and Wales: how can we explain them?."J ournal of the Royal Society of M edicine, 92 (6): 277-282.

(c) Copyright: J oaquín Recaño Valverde; Ana Chacón Martínez, 2021.

(c) Copyright: Scripta Nova, 2021.

Ficha bibliográfica:

RECAÑO VALVERDE, J oaquín y CHACÓN MARTíNEZ, Ana. Una geografía regional de los tipos de hogares en la Europa de la Segunda Transición Demogràfica. Scripta Nova. Revista Electrónica de Geografía y Ciencias Sociales. Barcelona: Universitat de Barcelona, vol. 25, Núm. 1(2021), p. 195-237.

[ISSN: 1138-97] 